\title{
Direct Stepwise Oxidation of Methane to Methanol
}

\section{over $\mathrm{Cu}-\mathrm{SiO}_{2}$}

\author{
Selmi E. Bozbag ${ }^{1,2, \dagger}$, Petr Sot ${ }^{1,2}$, Maarten Nachtegaal ${ }^{1}$, Marco Ranocchiari ${ }^{1}$, Jeroen A. van

$$
\text { Bokhoven }{ }^{1,2, *} \text {, Carl Mesters }{ }^{3, *}
$$ \\ ${ }^{1}$ Paul Scherrer Institute, Villigen, CH-5232 Switzerland.
}

${ }^{2}$ ETH Zurich, Institute for Chemical and Bioengineering, Wolfgang-Pauli-Strasse 10, CH-8093 Zurich, Switzerland.

${ }^{3}$ Shell Technology Center Houston, 3333 Highway 6 South, Houston, TX 77083, USA

KEYWORDS: Methane to methanol, silica, copper, activation temperature, XRD, XAS.

\begin{abstract}
Cu}$ supported on $\mathrm{SiO}_{2}$ can be used to directly convert methane to methanol in a stepwise process with no intrinsic need for a zeolite support. Effects of parameters such as the $\mathrm{O}_{2}$ activation temperature, activation time, $\mathrm{CH}_{4}$ reaction temperature, $\mathrm{CH}_{4}$ partial pressure $\left(\mathrm{p}_{\mathrm{CH}}\right)$ and $\mathrm{Cu}$ wt. \% on methanol yield were investigated. Increasing the $\mathrm{O}_{2}$ activation temperature in the 200-800 ${ }^{\circ} \mathrm{C}$ range significantly improved the methanol yield and when carried out at $800{ }^{\circ} \mathrm{C}$, a methanol yield of $11.5 \mu \mathrm{mol} / \mathrm{g}_{\text {catalyst }}$ was obtained after reaction with methane at $200{ }^{\circ} \mathrm{C}$ for the sample with 2 wt. $\% \mathrm{Cu}$. Yield per mole of $\mathrm{Cu}$ increased exponentially from 1.0 to $59.1 \mathrm{mmol}$ with decreased $\mathrm{Cu}$ wt. \% from 30 to 1 , respectively. The increase in the $\mathrm{O}_{2}$ activation time also strongly
\end{abstract}


influenced the yield which corresponded to the increase in yield by a factor of $>2$ between $1 \mathrm{~h}$ and 8h. Increasing $\mathrm{p}_{\mathrm{CH} 4}$ from 0.05 to 1 atm resulted in a 5 -fold increase in yield after activation at 450 ${ }^{\circ} \mathrm{C}$ however it resulted in at least $20 \%$ lower yields after activation at $800{ }^{\circ} \mathrm{C}$ showing that active sites of different nature were formed at different activation temperatures. The increase in yield with ramped $\mathrm{O}_{2}$ activation temperature correlated with the dehydration of the samples as evidenced by X-ray absorption near edge spectroscopy (XANES) and via mass spectroscopy (MS) traces of $\mathrm{H}_{2} \mathrm{O}$ during the $\mathrm{O}_{2}$ activation step.

\section{Introduction}

Direct conversion of methane into methanol using molecular oxygen remains one of the greatest challenges in catalysis. Although this reaction is thermodynamically possible, it is difficult to omit the kinetically controlled over-oxidation of methane since the desired product methanol is more reactive. This problem can be addressed by forming a stable complex of the reaction intermediate thereby preventing the total oxidation of methane to $\mathrm{CO}_{2}$ and then converting the intermediate to methanol in a step-wise process ${ }^{1-3}$.

Over the last decade a number of reports showed the potential of $\mathrm{Cu}$ loaded zeolites such as ZSM- $5^{4}$, mordenite ${ }^{5}$, small-pore zeolites ${ }^{6-8}$ and others ${ }^{9}$ for the conversion of methane to methanol. The stepwise (sub)stoichiometric process consists of the activation of $\mathrm{O}_{2}$ on active copper-oxo sites ${ }^{10-14}$ followed by the reaction of methane in which the oxidized copper sites react with methane to form a chemisorbed stable intermediate which allows the production of methanol via the subsequent hydration step either at process conditions 5,15 or via room temperature solvent extraction ${ }^{16}$. Processes using oxidants other than $\mathrm{O}_{2}{ }^{17-21}$ and a catalytic continuous process were also recently reported ${ }^{22}$. At ambient pressure, the formation of the 
active copper-oxo species requires the dehydration of the sample in a high temperature treatment typically $>400{ }^{\circ} \mathrm{C}^{23-24}$. At high temperature, the chemisorbed methane intermediate decomposes and therefore the subsequent reaction step is usually carried out at lower temperatures $\left(<250^{\circ} \mathrm{C}\right)$. The aforementioned stepwise process limits the over-oxidation of the chemisorbed intermediate and therefore results in highly selective methanol yields, ranging from 9 to $180 \mu \mathrm{mol} / \mathrm{g}_{\text {catalyst }}$. Differences in the yield were associated with the concentration of the active sites and the nature of their speciation ${ }^{15,25-26}$.

Controllable synthesis of the active copper sites on the zeolite surface is difficult since beside the aforementioned sites a variety of copper species including isolated ions, oligomers, clusters and nanoparticles could form depending on the copper loading, zeolite morphology, Al location within the zeolite and the synthesis method ${ }^{27-28}$. Careful manipulation of the synthesis conditions is necessary for higher yield; Grunder et al. suggested that formation of unselective $\mathrm{Cu}$-oxo clusters can be avoided by limiting the $\mathrm{pH}$ during the ion-exchange procedure below the point of zero charge of the surface silanol groups in the zeolite ${ }^{29-30}$. The formation of the active sites in Cu-zeolites has been a subject of many spectroscopic ${ }^{23,27-28,31-37}$ and computational studies ${ }^{38-42}$. A definite agreement about the structure of the active site or sites has not been reached so far. For the methane to methanol reaction, the nature and the reactivity of the active site is also highly influenced by the process parameters such as $\mathrm{O}_{2}$ activation temperature and $\mathrm{CH}_{4}$ reaction pressure. All of the aforementioned treatments could result in different active site speciation. Based on spectroscopic and computational studies, when the process is carried out at ambient pressure with an $\mathrm{O}_{2}$ activation step $>400{ }^{\circ} \mathrm{C}$, mono( $\mu$-oxo)dicopper in Cu-ZSM5 ${ }^{43}$ and Cu-SSZ$13 \& 39^{7}$, trans- $\mu-1,2-$ peroxo dicopper(II) in Cu-SSZ-13\&39, tricopper in Cu-HMOR ${ }^{25}$ and tetraneutral clusters in $\mathrm{Cu}-\mathrm{MOR}{ }^{40}$ were proposed as active sites. Papas et al. showed that the 
hydrated $\mathrm{Z}\left[\mathrm{Cu}{ }^{\mathrm{II}} \mathrm{OH}\right]$ monocopper sites were the precursors to the active sites in $\mathrm{Cu}-\mathrm{SSZ}-13$ and the activity correlated with the concentration of reducible $\mathrm{Cu}$ species ${ }^{8}$. Although absent in biological systems, the mono copper core is a thermodynamically favored species in zeolites ${ }^{23}$. Alayon et al. proposed an additional water-stable active $\mathrm{Cu}$ species for $\mathrm{Cu}-\mathrm{MOR}$ formed upon $\mathrm{O}_{2}$ activation at $450{ }^{\circ} \mathrm{C}$ followed by hydration at $200{ }^{\circ} \mathrm{C} 44$. When the step-wise process was carried out isothermally at $200{ }^{\circ} \mathrm{C}$ and the subsequent $\mathrm{CH}_{4}$ reaction step was carried out at high pressure, higher methanol yields were obtained and nanoparticles were proposed as the active sites based on ultraviolet-visible spectroscopy (UV-Vis) and transmission electron microscopy (TEM) data $^{45-46}$. The complicated formation mechanisms of active copper-oxo sites, which can result in a variety of active or inactive $\mathrm{Cu}$ species on zeolites, prompted us to investigate supports other than zeolites. For the partial oxidation of methane, $\mathrm{Cu}$-SBA15 catalyst showed appreciable formaldehyde selectivity at low $\mathrm{CH}_{4}$ conversions at $625{ }^{\circ} \mathrm{C}^{47}$. Among other supports, amorphous $\mathrm{SiO}_{2}$ could be an attractive alternative to synthetic zeolites. $\mathrm{Cu}-\mathrm{SiO}_{2}$ using a modified $\mathrm{SiO}_{2}$ with an $\mathrm{Al}_{2} \mathrm{O}_{3}$ content of $0.6 \mathrm{wt} \%(\mathrm{Si} / \mathrm{Al}=141)$ did not show appreciable activity for the conversion of methane to methanol ${ }^{4}$ most probably due to the absence of active sites which did not form on $\mathrm{SiO}_{2}$ at $\mathrm{O}_{2}$ activation temperatures below $500{ }^{\circ} \mathrm{C}$. Active $\mathrm{Cu}$-oxo sites might be formed on the silica surface at different conditions i.e. at higher $\mathrm{O}_{2}$ activation temperatures.

In this study, we show that the direct step-wise conversion of methane to methanol is possible on $\mathrm{Cu}-\mathrm{SiO}_{2}$ subsequent to the $\mathrm{O}_{2}$ activation at higher temperatures $\left(>500{ }^{\circ} \mathrm{C}\right)$ without the necessity of a zeolite support. The effects of activation temperature, activation duration, $\mathrm{CH}_{4}$ partial pressure during reaction and $\mathrm{Cu}$ wt. $\%$ on the methanol yield were investigated. $\mathrm{Cu}-\mathrm{SiO}_{2}$ catalysts were characterized using $\mathrm{N}_{2}$ adsorption, X-ray diffraction (XRD), temperature programmed desorption-mass spectroscopy (TPD-MS), UV-Vis , in-situ X-ray absorption 
spectroscopy (XAS) and Scanning transmission electron microscopy (STEM) during or after various stages of the catalytic process.

\section{Experimental}

\subsection{Catalyst Preparation and Activity}

$\mathrm{Cu}-\mathrm{SiO}_{2}$ with varying $\mathrm{Cu}$ loadings $(1,2,5,15,30$ wt. $\%)$ were prepared via pore-volume impregnation of a silica support (PQ Silica PD44011) with an ammonium copper carbonate stock solution. The ammonium copper carbonate solution was prepared by adding $250 \mathrm{~g}$ of $\left(\mathrm{NH}_{4}\right)_{2} \mathrm{CO}_{3}$ to $690 \mathrm{~g}$ of an ammonia solution (25\%). After stirring for $30 \mathrm{~min}$ at $30^{\circ} \mathrm{C}$, a clear solution was

obtained. Subsequently, $300 \mathrm{~g}$ of copper hydroxy carbonate was added, in portions of $60 \mathrm{~g}$ within 5 min to the vigorously stirred ammonia carbonate solution. The solution was then diluted to the desired metal content and impregnated to the silica support followed by drying at $150{ }^{\circ} \mathrm{C}$ and calcination at $400{ }^{\circ} \mathrm{C}$. The drying and calcination steps were carried out in air.

The activity tests were carried out in a continuous-flow fixed-bed reactor. The catalyst powder $(0.7 \mathrm{~g})$ was placed in the middle of a quartz tube reactor which was fitted into a tubular furnace. Gas flows were regulated using calibrated mass flow controllers (Bronkhorst). Figure 1 shows the two different reaction protocols employed. All gas flows were kept at $30 \mathrm{~mL} / \mathrm{min}$ (1 atm, $\left.25^{\circ} \mathrm{C}\right)$. The first reaction protocol is hereafter referred to as $\mathrm{R} 1$ : A stream of $\mathrm{O}_{2}$ was introduced into the reactor and the reactor was heated to the desired activation temperature with a ramp of $1{ }^{\circ} \mathrm{C} / \mathrm{min}$ and remained at this temperature for a desired period. This was followed by cooling and removing the excess $\mathrm{O}_{2}$ with a $\mathrm{He}$ stream for $30 \mathrm{~min}$. $\mathrm{A} \mathrm{CH}_{4}$ stream $(5 \%$ in $\mathrm{He})$ was then introduced for $30 \mathrm{~min}$. Finally, the system was cooled down to room temperature under $\mathrm{He}$ flow for methanol quantification by extraction (described below). The second reaction protocol 
(hereafter referred to as R2) was similar to that of the first one except methanol was extracted using steam at $200{ }^{\circ} \mathrm{C}$ just after the $\mathrm{CH}_{4}$ reaction step (Step G2 in Figure 1). Steam was supplied using a controlled evaporator mixer (CEM W202A, Bronkhorst) with a rate of $10 \mathrm{~g} / \mathrm{h}$ where $\mathrm{He}$ (30 $\mathrm{ml} / \mathrm{min}$ ) was used as carrier gas. The evaporator temperature was set to $120{ }^{\circ} \mathrm{C}$. All the lines between the evaporator and reactor were heated to $120{ }^{\circ} \mathrm{C}$ to avoid condensation. A condenser, cooled down to $15^{\circ} \mathrm{C}$, was connected at the outlet of the reactor where the extract was condensed. Liquid samples containing a mixture of water and methanol were taken from the bottom of the condenser at desired intervals. Once the extraction was completed (as analyzed by gas chromatography (GC), Agilent 6890), a second cycle was initiated with heating from $200{ }^{\circ} \mathrm{C}$ in $\mathrm{O}_{2}$ to the desired activation temperature. Reactor downstream concentrations were monitored using a quadrupole mass spectrometer (Pfeiffer, SEM voltage $1050 \mathrm{~V}$, CH-TRON detector).

\subsection{Methanol quantification}

In the first reaction protocol the amount of produced methanol was quantified by extraction with liquid water (Step G1). After the reaction with $\mathrm{CH}_{4}$ and cooling, the catalyst was transferred into a vial along with a magnetic stirring bar and $2 \mathrm{~mL}$ MilliQ water was added. The vial was closed and the mixture was stirred for $2 \mathrm{~h}$. The suspension was filtered through a glass-fiber filter. Afterwards, $10 \mu \mathrm{l}$ acetonitrile (internal standard, $10 \% \mathrm{~V} / \mathrm{V}$ solution in water) was added and the mixture was analyzed on an Agilent 6890 GC equipped with a Restek Rtx ${ }^{\circledR}-5$ column ( $30 \mathrm{~m}, \mathrm{ID}=0.25 \mathrm{~mm}$, film thickness $0.25 \mu \mathrm{m}$ ) and a flame ionization detector. The oven temperature was held at $38{ }^{\circ} \mathrm{C}$ for $20 \mathrm{~min}$ and subsequently raised to $200{ }^{\circ} \mathrm{C}$ at $50{ }^{\circ} \mathrm{C} / \mathrm{min}$ and held there for $7 \mathrm{~min}$. Solvent extraction was repeated at least twice until no more methanol was obtained. The experimental error in methanol yield was $\pm 1 \mu \mathrm{mol} / \mathrm{g}_{\text {catalyst. }}$ In the second reaction 
protocol, after the liquid samples were taken from the outlet of the condenser (Step G2), acetonitrile was added as internal standard to the sample and the mixture was analyzed by GC.

\subsection{Characterization of the catalysts}

Textural properties of the samples were determined by $\mathrm{N}_{2}$ adsorption using a Micromeritics Tristar II 3020 instrument. Approximately $100 \mathrm{mg}$ of each material was transferred into the measurement tube, degassed at $50 \mathrm{mTorr}$ at $150{ }^{\circ} \mathrm{C}$ overnight and analyzed. The total pore volume $\left(V_{\text {total }}\right)$ was obtained using the uptake amount at $\mathrm{P} / \mathrm{P}^{0}=0.986$ and micropore volume $\left(V_{\text {micro }}\right)$ was obtained using the t-plot method. The Brunauer, Emmett and Teller (BET) surface areas of the samples were also measured. XRD measurements were carried out using a $\mathrm{Cu} \mathrm{Ka}$ source in a Bruker D8 Advance diffractometer. UV-Vis measurements were carried out in a measurement cell which was placed inside a glove bag filled with Ar. After treating the samples at various reactive steps described in Fig. 1, Ar was led to flow through the catalyst bed. Then, the quartz tubular reactor containing the catalyst bed was quickly removed from the test rig and transferred into the glove bag. Catalyst was then transferred into PMMA cuvettes and spectra were measured. The UV probe (reflection/backscattering, QR400-7-SR-125F, OD=3.18mm), connected by an optical fiber to the spectrometer, was positioned at the center of the PMMA cuvette which was fitted on a holder to obtain a good signal to noise ratio. The measurement cell was placed in a dark box to minimize stray light. UV-Vis spectra were recorded by a Maya 2000 Pro (Ocean Optics, Spectra Suite 2000) spectrometer at a scan rate of $200 \mathrm{~ms}$ per spectrum from $35000 \mathrm{~cm}^{-1}$ to $10000 \mathrm{~cm}^{-1}$. A thousand scans were averaged to produce a single spectrum. A spectrum of the bare $\mathrm{SiO}_{2}$ was used as reference. The morphologies of the catalysts were 
characterized by STEM on the aberration-corrected HD-2700CS (Hitachi; cold-field emitter), operated at an acceleration potential of $200 \mathrm{kV}$. A probe corrector (CEOS) is incorporated in the microscope column between the condenser lens and the probe-forming objective lens providing excellent high-resolution capability (beam diameter ca. $0.1 \mathrm{~nm}$ in the selected ultra-high resolution mode). Images (1024 x 1024 pixels) were recorded with a high-angle annular dark field (HAADF) detector with frame times of ca $15 \mathrm{~s}$. These imaging conditions give rise to atomic number ( $\mathrm{Z}$ ) contrast, a highly sensitive method to detect even atoms of strongly scattering elements (high Z) on light supports. TEM was performed on a F30 microscope (FEI; field emission gun), operated at an acceleration potential of $300 \mathrm{kV}$. XAS spectra around the $\mathrm{Cu} \mathrm{K}-$ edge were collected at the SuperXAS beamline, Swiss Light Source (SLS), of the Paul Scherrer Institute in Villigen, Switzerland. The SLS ring is operated in top up mode at $400 \mathrm{~mA}$ and 2.4 $\mathrm{GeV}$. The polychromatic beam from the 2.9 Tesla superbend source was collimated with a Sicoated collimating mirror at $2.5 \mathrm{mrad}$. This also served to remove higher harmonics. The $\mathrm{X}$-ray beam was subsequently monochromatized by a channel-cut monochromator using a $\mathrm{Si}(111)$ crystal pair. Focusing of the beam to a spot size of $500 \times 100(\mathrm{H} \mathrm{x} \mathrm{V})$ micrometer $^{2}$ was achieved using a Rh-coated toroidal mirror. Spectra were measured in transmission mode using $15 \mathrm{~cm}$ long ion chambers filled with $20 \% \mathrm{He} / 80 \% \mathrm{~N}_{2}$ mixture resulting in about $8 \%$ absorption in both. $\mathrm{A} \mathrm{Cu}$ foil mounted in front of a third ionization chamber filled with $100 \% \mathrm{~N}_{2}$ at 1.5 bar was measured simultaneously and used for absolute energy calibration. Around $15 \mathrm{mg}$ of $\mathrm{Cu}-\mathrm{SiO}_{2}$ was fixed between two plugs of quartz wools and placed in a $3 \mathrm{~mm}$ diameter, thin-walled quartz capillary reactor. This was affixed to an air blower set-up for controlled heating. The temperature inside the capillary reactor was pre-calibrated against the readout temperature of the blowing hot air with a thermocouple inserted in the reactor until the thermocouple's tip touched the middle of 
the catalyst bed. Subsequently, the thermocouple was removed during the experimental measurements and the air blower was set against the calibrated settings.

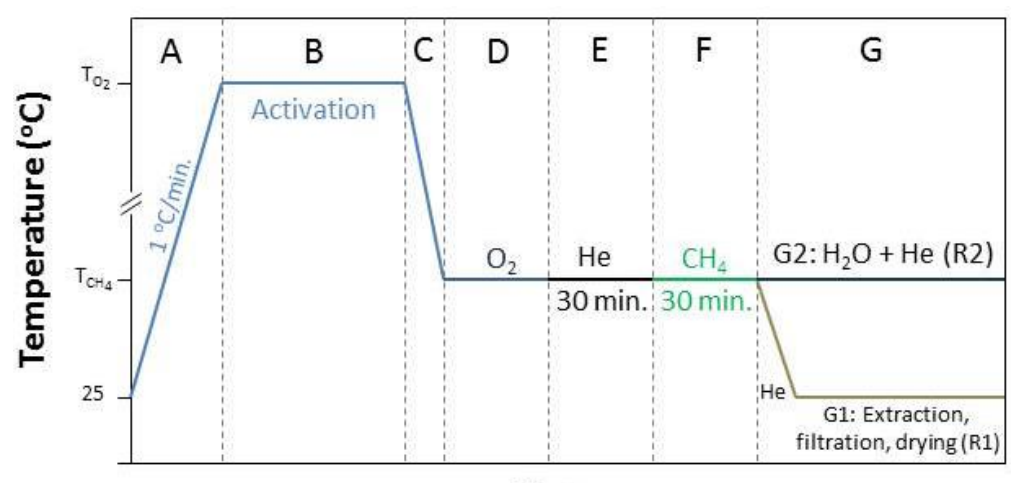

Time

Figure 1. Schematic diagram of the thermal and chemical treatments on $\mathrm{Cu}$-Silica samples during one catalytic cycle. A-D: activation; E: He purge; F: $\mathrm{CH}_{4}$ reaction; G: hydration and methanol production. ( $\mathrm{T}_{\mathrm{O} 2}$ and $\mathrm{T}_{\mathrm{CH} 4}$ represent the $\mathrm{O}_{2}$ activation and $\mathrm{CH}_{4}$ reaction temperatures, respectively).

\section{Results and Discussion}

\subsection{Catalytic Activity}

The samples screened in this study were 1, 2, 5, 15 and $30 \mathrm{wt} . \% \mathrm{Cu}$ containing $\mathrm{Cu}-\mathrm{SiO}_{2}$ which are hereafter referred to as $\mathrm{Cu}-\mathrm{SiO}_{2}-1, \mathrm{Cu}-\mathrm{SiO}_{2}-2, \mathrm{Cu}-\mathrm{SiO}_{2}-5, \mathrm{Cu}-\mathrm{SiO}_{2}-15$ and $\mathrm{Cu}-\mathrm{SiO}_{2}-30$, respectively. All of the methanol yields reported were obtained using reaction protocol R1 unless otherwise mentioned. The formation of active copper-oxo species in zeolites is significantly influenced by the $\mathrm{O}_{2}$ activation temperature. Therefore, the effect of the activation temperature on the methanol yield was studied (Fig. 2). For both $\mathrm{Cu}-\mathrm{SiO}_{2}-2$ and $\mathrm{Cu}-\mathrm{SiO}_{2}-5$ very low methanol yields $\left(0.7 \mu \mathrm{mol} / \mathrm{g}_{\text {catalyst, }}\right.$ measured via G1) were obtained up to an activation 
temperature of $450{ }^{\circ} \mathrm{C}$ followed by exposure to $\mathrm{CH}_{4}\left(5 \% \mathrm{CH}_{4}\right.$ in $\left.\mathrm{He}\right)$ at $200{ }^{\circ} \mathrm{C}$. Methanol yield increased significantly as the $\mathrm{O}_{2}$ activation temperature increased up to $800{ }^{\circ} \mathrm{C}$ reaching 11.5 and $7.9 \mu \mathrm{mol} / \mathrm{g}_{\text {catalyst }}$ for $\mathrm{Cu}-\mathrm{SiO}_{2}-2$ and $\mathrm{Cu}-\mathrm{SiO}_{2}-5$, respectively. The yield obtained from the $\mathrm{Cu}-$ $\mathrm{SiO}_{2}-2$ is even higher than that reported for many Cu-zeolite systems ${ }^{4,9}$. The reusability of the $\mathrm{Cu}-\mathrm{SiO}_{2}-2$ in a subsequent catalytic cycle was also tested using reaction protocol $\mathrm{R} 2$ and resulted in a very similar methanol yield (Fig. 2). When a reaction cycle using $\mathrm{Cu}-\mathrm{SiO}_{2}-5$ with $\mathrm{O}_{2}$ activation at $800{ }^{\circ} \mathrm{C}$ is followed by a reaction cycle with $\mathrm{O}_{2}$ activation at $450{ }^{\circ} \mathrm{C}$, the methanol yield drops from $7.9 \mu \mathrm{mol} / \mathrm{g}_{\text {catalyst }}$ in the $1^{\text {st }}$ cycle to $1.9 \mu \mathrm{mol} / \mathrm{g}_{\text {catalyst }}$ in the $2^{\text {nd }}$ cycle showing the importance of high temperature activation. Data in Fig. 2 also shows the effect of methane partial pressure on the methanol yield. The increase of methane partial pressure from 0.05 to $1 \mathrm{~atm}$ resulted in an increase of the methanol yield from 0.73 and 0.5 to $4.8 \mu \mathrm{mol} / \mathrm{g}_{\text {catalyst }}$ for both catalysts after $\mathrm{O}_{2}$ activation at $450{ }^{\circ} \mathrm{C}$ for the $\mathrm{Cu}-\mathrm{SiO}_{2}-2$ and $\mathrm{Cu}-\mathrm{SiO}_{2}-5$, respectively. For the $\mathrm{Cu}-$ $\mathrm{SiO}_{2}-2$, the increase of partial pressure increased the yield after $\mathrm{O}_{2}$ activation at $650{ }^{\circ} \mathrm{C}$ but decreased the yield after $\mathrm{O}_{2}$ activation at $800{ }^{\circ} \mathrm{C}$. 


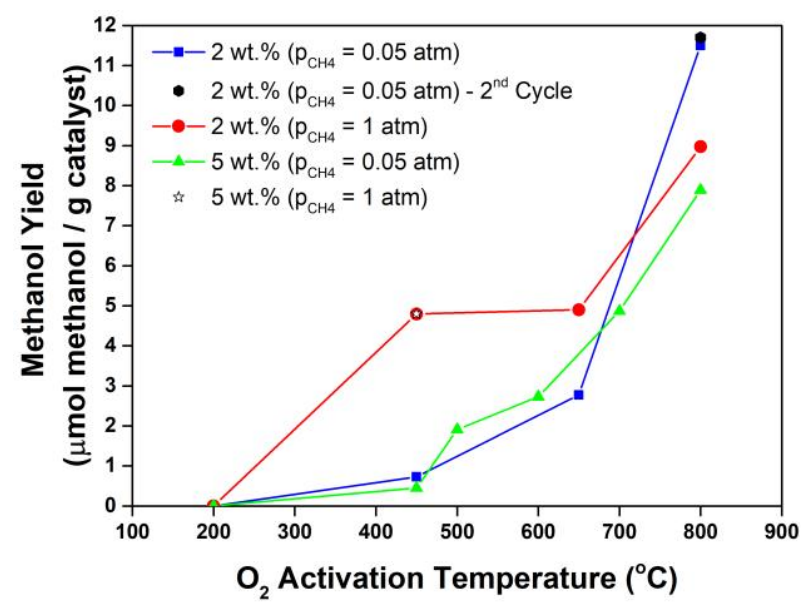

Figure 2. Effect of $\mathrm{O}_{2}$ activation temperature (for 8 hours) on methanol yield $\left(\mathrm{CH}_{4}\right.$ reaction was carried out at $200{ }^{\circ} \mathrm{C}$ and the $\mathrm{p}_{\mathrm{CH} 4}$ denotes the partial pressure of $\mathrm{CH}_{4}$ during Step $\mathrm{F}$ of the catalytic cycle).
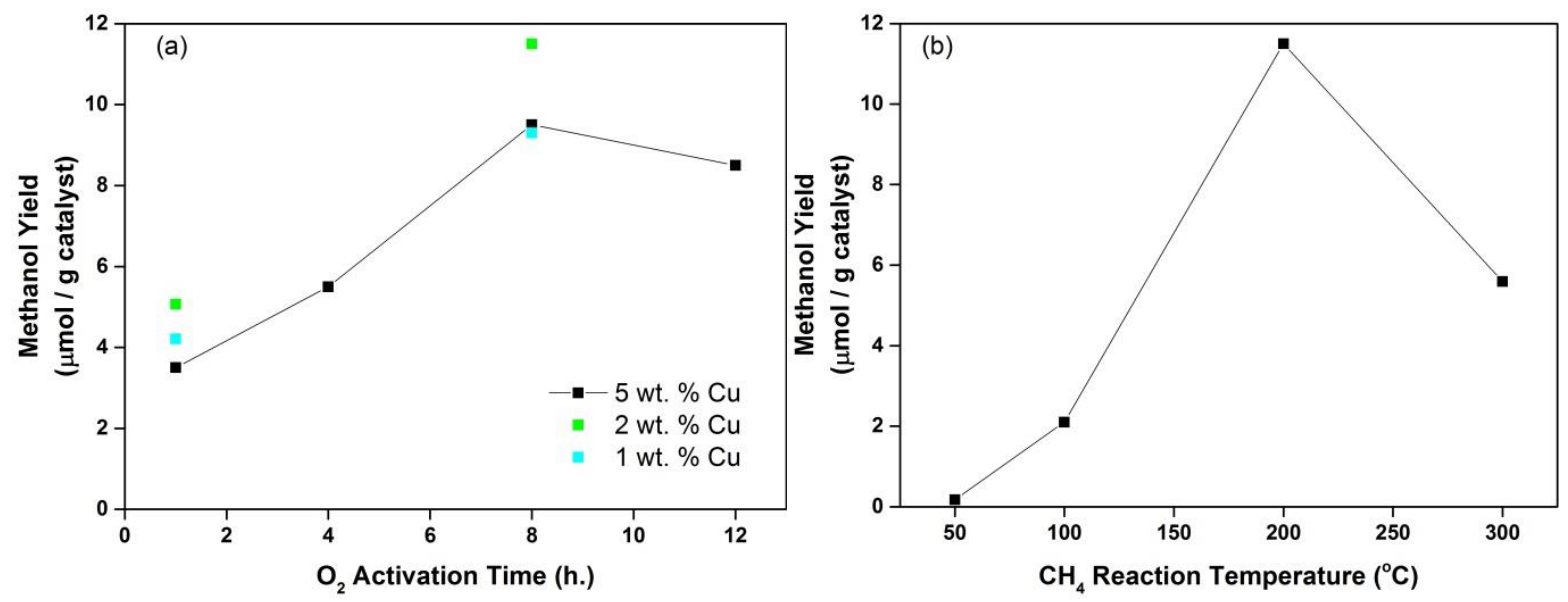

Figure 3. Effect of (a) activation time and (b) $\mathrm{CH}_{4}$ reaction temperature on the methanol yield. Activation was carried out in $\mathrm{O}_{2}$ at $800{ }^{\circ} \mathrm{C}$.

Fig. 3a shows the effect of the activation time on the methanol yield when the activation was carried out at $800{ }^{\circ} \mathrm{C}$. Data clearly indicate an increase in methanol yield with activation time up to $8 \mathrm{~h}$ where the yield increased from 3.5 to $9.5 \mu \mathrm{mol} / \mathrm{g}_{\text {catalyst }}$ for $\mathrm{Cu}-\mathrm{SiO}_{2}-5$. The yield did not 
change considerably after an activation time of $12 \mathrm{~h} . \mathrm{Cu}-\mathrm{SiO}_{2}-1$ and $\mathrm{Cu}-\mathrm{SiO}_{2}-2$ showed a similar trend. Thus, with increased $\mathrm{O}_{2}$ exposure time, the number of reactive sites increased. The temperature of the $\mathrm{CH}_{4}$ reaction step has also an effect on the yield (Fig. 3b). The yield increased from 0.2 to $11.5 \mu \mathrm{mol} / \mathrm{g}_{\text {catalyst }}$ as the $\mathrm{CH}_{4}$ reaction temperature was raised from 50 to $200{ }^{\circ} \mathrm{C}$ for $\mathrm{Cu}-\mathrm{SiO}_{2}-2$. As the $\mathrm{CH}_{4}$ reaction temperature was further increased to $300{ }^{\circ} \mathrm{C}$, the yield dropped to $5.6 \mu \mathrm{mol} / \mathrm{g}_{\text {catalyst }}$ due to over-oxidation and the decomposition of the reacted methane intermediate. Similar results were also obtained for $\mathrm{Cu}$-chabazite where $\mathrm{CH}_{4}$ reaction temperatures higher than $200{ }^{\circ} \mathrm{C}$ resulted in decreased methanol yield and decreased selectivity ${ }^{8}$.

Previous reports on $\mathrm{Cu}$-zeolites showed that the $\mathrm{Cu}$ loading is an important parameter that affects the methanol yield. $\mathrm{Cu}$ loading in zeolites affect the formation of active sites i.e. at lower loadings (typically $\mathrm{Cu} / \mathrm{Al}<0.2^{48}$ ) monoatomic species exist and as the loading is increased di- or tri-copper species or clusters may form. In zeolites active site formation is dictated by the location of Al within the framework. Fig. 4 depicts the variation of the methanol yield with $\mathrm{Cu}$ wt. \% in $\mathrm{Cu}-\mathrm{SiO}_{2}$. Different trends in the methanol yield with $\mathrm{Cu}$ wt. \% were observed for different activation temperatures (Fig. 4a). When the $\mathrm{O}_{2}$ activation was carried out at $800{ }^{\circ} \mathrm{C}$ followed by $\mathrm{CH}_{4}$ reaction at $200{ }^{\circ} \mathrm{C}$ with a $\mathrm{CH}_{4}$ partial pressure of $0.05 \mathrm{~atm}$, methanol yield per gram catalyst increased with increasing $\mathrm{Cu}$ wt. $\%$ where the highest value of $11.5 \mu \mathrm{mol} / \mathrm{g}_{\text {catalyst }}$ was reached with $\mathrm{Cu}-\mathrm{SiO}_{2}-2$. After this point, the yield decreased with increasing $\mathrm{Cu}$ wt. \%. A bare silica sample treated with the same reactive steps of the catalytic cycle as the other catalysts did not show any methanol yield (Fig. $4 \mathrm{a}$ ). When the activation was carried out at $450{ }^{\circ} \mathrm{C}$, the yield was considerably smaller for all the samples independent of the metal loading. $\mathrm{Cu}_{-} \mathrm{SiO}_{2}-1$ did not show any appreciable yield whereas as the metal loading was further increased, the yield was increased and a plateau was reached for $\mathrm{Cu}-\mathrm{SiO}_{2}-2$. When the $\mathrm{CH}_{4}$ partial pressure was 1 
atm during the $\mathrm{CH}_{4}$ reaction step (step F), at least four times higher yields $\left(4.8 \mu \mathrm{mol} / \mathrm{g}_{\text {catalyst }}\right.$ ) were obtained as compared to the case of 0.05 atm for both $\mathrm{Cu}-\mathrm{SiO}_{2}-2$ and $\mathrm{Cu}-\mathrm{SiO}_{2}-5$. Lower yields were obtained when $\mathrm{CH}_{4}$ partial pressure was 1 atm after $\mathrm{O}_{2}$ activation at $800{ }^{\circ} \mathrm{C}$ as compared to the same case with a $\mathrm{CH}_{4}$ partial pressure of $0.05 \mathrm{~atm}$. This suggests a difference in the nature and the concentration of the active sites for the $\mathrm{O}_{2}$ activation temperatures of 450 and $800{ }^{\circ} \mathrm{C}$. Fig. $4 \mathrm{~b}$ illustrates the variation of the methanol yield per mole of copper in the catalyst. After the $\mathrm{O}_{2}$ activation at $800{ }^{\circ} \mathrm{C}$ followed by a $\mathrm{CH}_{4}$ reaction step at $200{ }^{\circ} \mathrm{C}\left(\mathrm{p}_{\mathrm{CH} 4}=0.05 \mathrm{~atm}\right)$, the methanol yield per mole of $\mathrm{Cu}$ increased with decreasing metal loading in the 1-30 wt. \% range with $\mathrm{Cu}-\mathrm{SiO}_{2}-1$ resulting in a yield of $59.1 \mathrm{mmol} / \mathrm{mol} \mathrm{Cu}$. This shows that the concentration of the active $\mathrm{Cu}$ sites is higher for samples with a lower $\mathrm{Cu}$ content. However, the trend upto 2 wt. $\%$ is different when $\mathrm{p}_{\mathrm{CH} 4}=1 \mathrm{~atm}\left(\mathrm{O}_{2}\right.$ activation at $\left.800^{\circ} \mathrm{C}\right)$. Here, the highest yield (per mol of $\mathrm{Cu}$ ) was obtained for the $2 \mathrm{wt} . \%$ sample. This again shows that the nature of the active sites differs at different $\mathrm{CH}_{4}$ reaction partial pressures. On the other hand, these different active sites may be present for each partial pressure value but with different reaction orders in $\mathrm{CH}_{4}$ activation resulting in different methanol yields. 

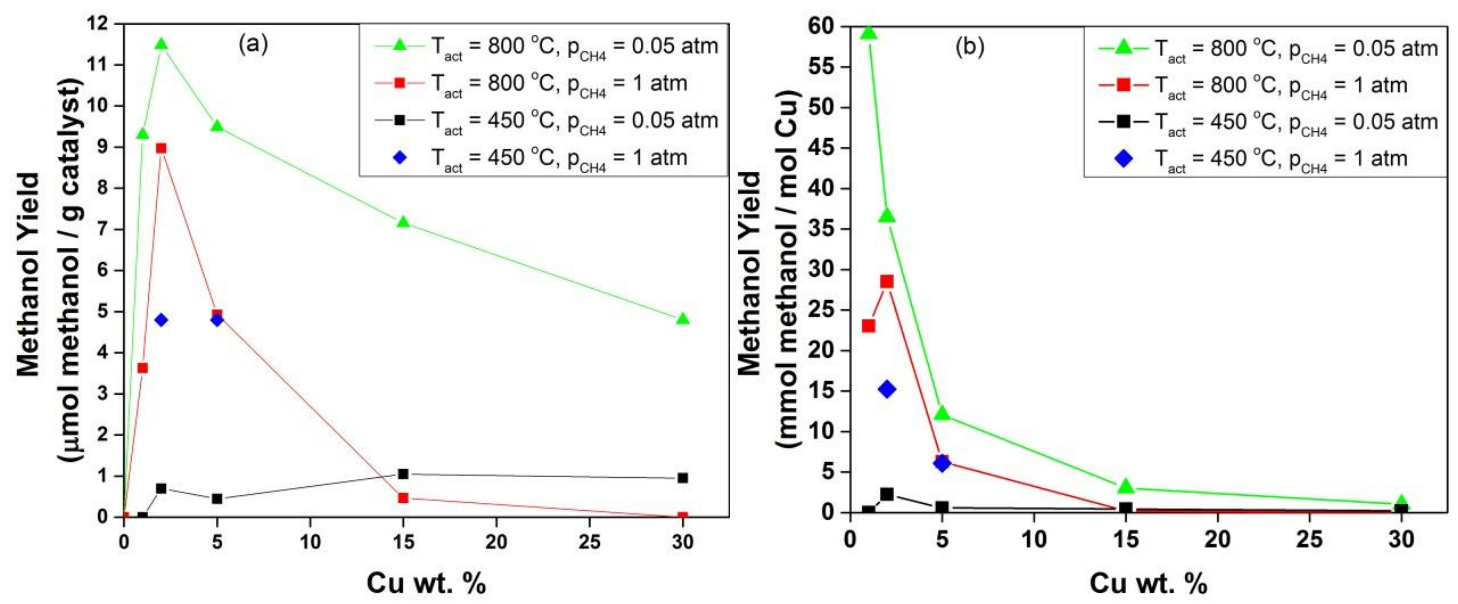

Figure 4. Effect of $\mathrm{Cu}$ wt. $\%$ on methanol yield. (a) micromoles methanol $/ \mathrm{g}_{\text {catalyst }}$ (b) $\mathrm{mmol}$ methanol / mol Cu. $\mathrm{p}_{\mathrm{CH} 4}$ denotes the partial pressure of $\mathrm{CH}_{4}$ during Step $\mathrm{F}$ of the catalytic cycle.

\subsection{Catalyst Characterization}

Table 1 shows the textural properties of the samples investigated in this study. The fresh silica sample had a pore volume of $1.65 \mathrm{~cm}^{3} / \mathrm{g}$ with BET surface area of $260 \mathrm{~m}^{2} / \mathrm{g}$ with low concentration of micropores $\left(0.013 \mathrm{~cm}^{3} / \mathrm{g}\right)$ as compared to the total pore volume. The pore volume and thus the BET surface area decreased from $1.31 \mathrm{~cm}^{3} / \mathrm{g}$ and $276 \mathrm{~m}^{2} / \mathrm{g}$ to $0.70 \mathrm{~cm}^{3} / \mathrm{g}$ and $201 \mathrm{~m}^{2} / \mathrm{g}$ when the $\mathrm{Cu}$ wt. \% increased from 1 to 30 , respectively. At the end of one catalytic cycle, the micropore volume for all samples decreased slightly. 
Table 1 Textural properties of the samples

\begin{tabular}{|c|c|c|c|}
\hline \multicolumn{4}{|l|}{ Fresh samples } \\
\hline Samples & $\begin{array}{l}\text { BET surface } \\
\text { area }\left(\mathrm{m}^{2} / \mathrm{g}\right)\end{array}$ & $\begin{array}{l}\text { t-plot Micropore } \\
\text { volume } \\
\left(\mathrm{cm}^{3} / \mathrm{g}\right)\end{array}$ & $\begin{array}{l}\text { Pore volume } \\
\left(\mathrm{cm}^{3} / \mathrm{g}\right)\end{array}$ \\
\hline 0 (bare silica) & 260 & 0.013 & 1.65 \\
\hline $\mathrm{Cu}-\mathrm{SiO}_{2}-1$ & 276 & 0.012 & 1.31 \\
\hline $\mathrm{Cu}-\mathrm{SiO}_{2}-2$ & 269 & 0.012 & 1.34 \\
\hline $\mathrm{Cu}-\mathrm{SiO}_{2}-5$ & 213 & 0.027 & 0.98 \\
\hline $\mathrm{Cu}-\mathrm{SiO}_{2}-15$ & 200 & 0.035 & 0.77 \\
\hline $\mathrm{Cu}-\mathrm{SiO}_{2}-30$ & 201 & 0.028 & 0.70 \\
\hline \multicolumn{4}{|c|}{ Post-cycle* samples } \\
\hline $\mathrm{Cu}-\mathrm{SiO}_{2}-1$ & 240 & 0.009 & 1.12 \\
\hline $\mathrm{Cu}-\mathrm{SiO}_{2}-2$ & 229 & 0.008 & 1.07 \\
\hline $\mathrm{Cu}-\mathrm{SiO}_{2}-5$ & 200 & 0.011 & 1.24 \\
\hline $\mathrm{Cu}-\mathrm{SiO}_{2}-15$ & 204 & 0.006 & 0.85 \\
\hline $\mathrm{Cu}-\mathrm{SiO}_{2}-30$ & 184 & 0.005 & 0.70 \\
\hline
\end{tabular}

* As depicted in Fig. 1. 

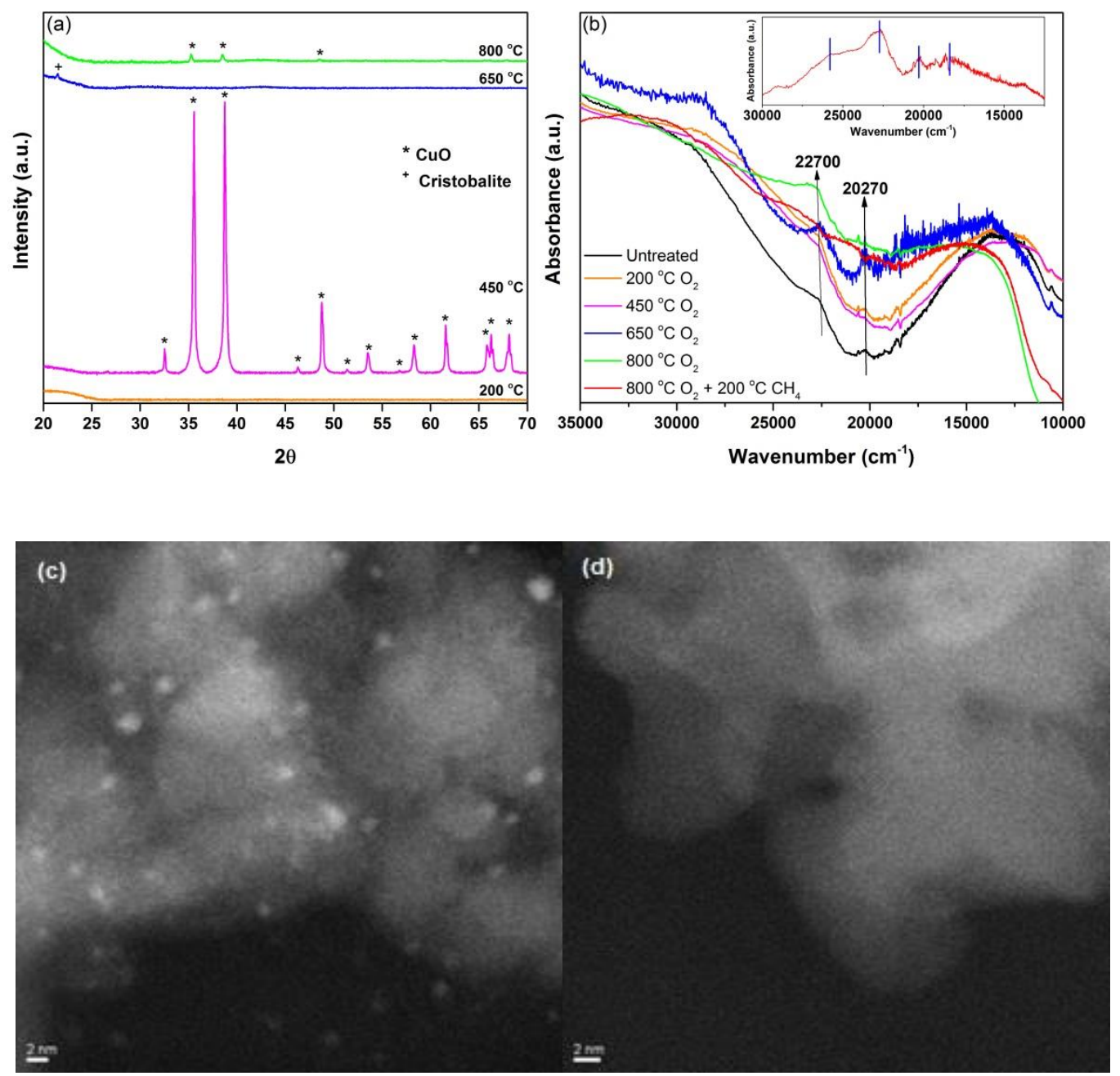

Figure 5. (a) $\mathrm{XRD}$ of $\mathrm{Cu}-\mathrm{SiO}_{2}-2$ after calcination at various temperatures in $\mathrm{O}_{2}$. (b) Room temperature (RT) UV-Vis spectra of $\mathrm{Cu}-\mathrm{SiO}_{2}-2$ after calcination at various temperatures in $\mathrm{O}_{2}$ and after $\mathrm{CH}_{4}$ reaction $\left(\mathrm{O}_{2}\right.$ activated at $\left.800{ }^{\circ} \mathrm{C}\right)$. Arrows indicate changes in the particular feature with respect to previous temperature increment. Inset shows the difference spectrum between $\mathrm{O}_{2}$ activated $\left(800^{\circ} \mathrm{C}\right)$ and $\mathrm{CH}_{4}$ reacted $\left(200^{\circ} \mathrm{C}\right)$ sample. (c) Z-contrast $\mathrm{STEM}$ image after $\mathrm{O}_{2}$ activation at 450 and at (d) $800{ }^{\circ} \mathrm{C}$.

Figure 5 presents the effect of $\mathrm{O}_{2}$ activation temperature on the structural and spectroscopic features in $\mathrm{Cu}-\mathrm{SiO}_{2}-2$. Fig. 5a shows the XRD patterns after $\mathrm{O}_{2}$ activation at various temperatures. No crystallinity was observed for either fresh $\mathrm{Cu}-\mathrm{SiO}_{2}$ (not shown) or after the $\mathrm{O}_{2}$ 
activation at $200{ }^{\circ} \mathrm{C}$. Monoclinic $\mathrm{CuO}$ with sharp peaks were clearly observed after $\mathrm{O}_{2}$ activation at $450{ }^{\circ} \mathrm{C}$ with an average diameter of $30 \mathrm{~nm}$ as calculated using the Scherrer equation. An exemplar STEM image which is shown in Fig. 5c displays well dispersed $\mathrm{CuO}$ nanoparticles on $\mathrm{SiO}_{2}$ with average nanoparticle size of $1-2 \mathrm{~nm}$. The small nanoparticles most probably formed during the prolonged exposure to the electron beam as illustrated in Fig. 6. Here, one can clearly observe the sintering of a $\mathrm{CuO}$ nanoparticle indicated with the white arrow until it reaches a size of $2.9 \mathrm{~nm}$. This suggests that there is a mixture of bulk $\mathrm{CuO}$ crystallites with larger size that were absent in the regions analyzed by the STEM and highly dispersed $\mathrm{Cu}$ on the surface of $\mathrm{SiO}_{2}$ after the $\mathrm{O}_{2}$ activation. Surface mixtures of highly dispersed and bulk $\mathrm{CuO}$ was also previously reported on $\mathrm{SiO}_{2}$ supported catalysts ${ }^{50-51}$. Further increase in the $\mathrm{O}_{2}$ activation temperature to 650 ${ }^{\circ} \mathrm{C}$ resulted in the complete disappearance of the $\mathrm{CuO}$ reflections in the XRD pattern. At $650{ }^{\circ} \mathrm{C}$, a small peak assigned to cristobalite phase was observed in line with the literature on $\mathrm{Cu}-\mathrm{SiO}_{2}$ treated at similar temperatures ${ }^{52-53}$. We hypothesize that the disappearance of $\mathrm{CuO}$ crystal peaks might be due a number of phenomena including the formation of dispersed $\mathrm{Cu}$ species, doping of $\mathrm{Cu}$ into the $\mathrm{SiO}_{2}$ matrix due to partial crystallization of the support or the formation of amorphous islands. At $800{ }^{\circ} \mathrm{C}$, peaks associated with (002) and (111) planes of $\mathrm{CuO}$ at $2 \theta$ angles of 35.4 and 38.7 , respectively were observed with a very small intensity indicating that a small portion of copper formed $\mathrm{CuO}$ crystals. Since the $\mathrm{XRD}$ was performed subsequent to the cooling down subsequent to the $800{ }^{\circ} \mathrm{C} \mathrm{O}_{2}$ activation, some crystallization might have occurred leading to some small $\mathrm{CuO}$ reflections. STEM images taken after $\mathrm{O}_{2}$ activation at $800{ }^{\circ} \mathrm{C}$ did not show any nanoparticles (Fig 5d). This indicates that $\mathrm{CuO}$ nanoparticle concentration is very low and the rest of $\mathrm{Cu}$ is either in amorphous form or in very small particles that are not detected. 


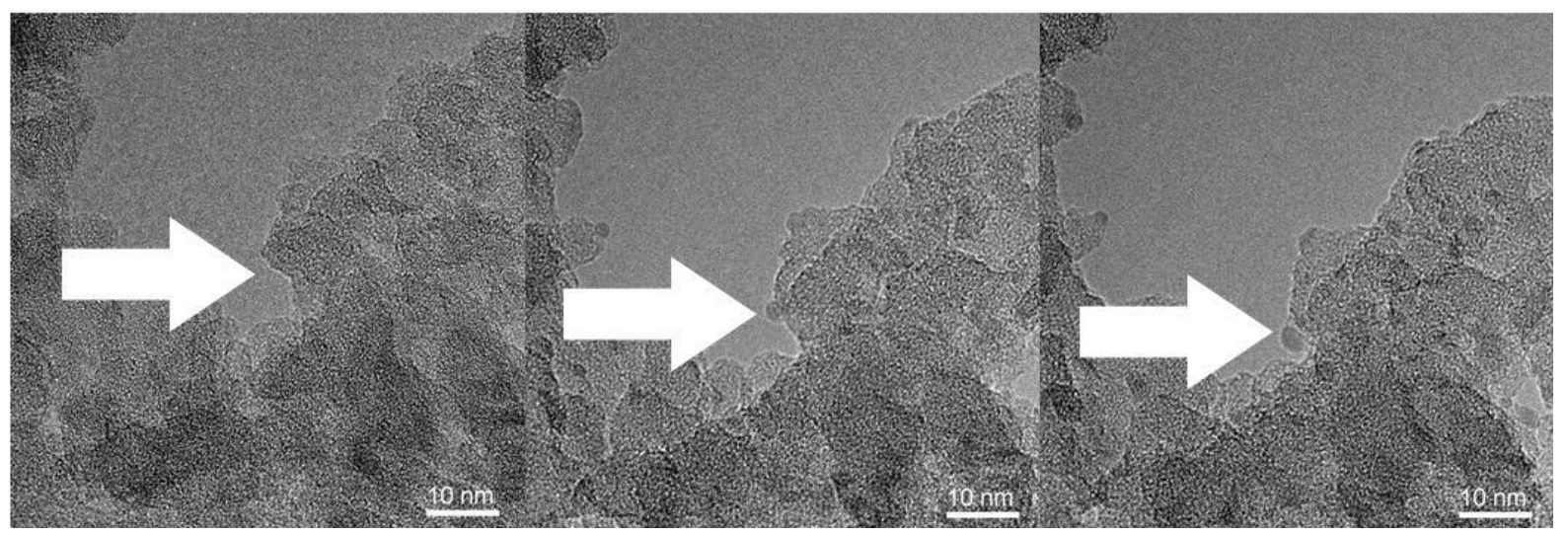

Figure 6. Bright Field TEM image of fresh $\mathrm{Cu}-\mathrm{SiO}_{2}-15$ taken during exposure to the electron beam. The white arrow indicates the growth of a copper oxide nanoparticle on the $\mathrm{SiO}_{2}$ surface with time.

$\mathrm{UV}$-vis spectroscopy is often used to elucidate the nature of the active copper-oxo sites in $\mathrm{Cu}-$ zeolites ${ }^{4-5,32,54-57}$. Fig $5 \mathrm{~b}$ shows the UV-Vis spectra of the $\mathrm{Cu}-\mathrm{SiO}_{2}$ samples after $\mathrm{O}_{2}$ activation at various temperatures along with the spectrum taken after the $\mathrm{CH}_{4}$ reaction at $200{ }^{\circ} \mathrm{C}$ (subsequent to $\mathrm{O}_{2}$ activation at $800{ }^{\circ} \mathrm{C}$ ). The charge transfer $(\mathrm{CT})$ band at $22700 \mathrm{~cm}^{-1}$ was observed for all samples and its intensity increased with increasing activation temperature. The shape of the band became much more distinct as the $\mathrm{O}_{2}$ activation temperature was raised above $450{ }^{\circ} \mathrm{C}$. The feature at $22700 \mathrm{~cm}^{-1}$ associated with mono( $\mu$-oxo)dicopper on $\mathrm{Cu}-\mathrm{ZSM} 5^{43}$ and was also observed in $\mathrm{Cu}-\mathrm{MOR}{ }^{5,32,54}$ was previously suggested as the active site for the direct conversion of methane to methanol. The $\mathrm{d}-\mathrm{d}$ band at $20000 \mathrm{~cm}^{-1}$ was associated with other active (di-)copper species in zeolites ${ }^{34}$. The formation of these active (di-)copper species in zeolites was closely associated with the dehydration of the sample therefore we monitored the MS traces of $\mathrm{H}_{2} \mathrm{O}$ during the $\mathrm{O}_{2}$ activation step of $\mathrm{Cu}-\mathrm{SiO}_{2}-2$ (Fig. 7). Here, two broad $\mathrm{H}_{2} \mathrm{O}$ desorption peaks could clearly be observed with peak centers at 315 and $608{ }^{\circ} \mathrm{C}$ with distinct shoulders at $130{ }^{\circ} \mathrm{C}$, and $800{ }^{\circ} \mathrm{C}$, respectively. The dehydration of $\mathrm{Cu}-\mathrm{SiO}_{2}$ continued with the on-set of an 
isothermal dehydration at $800{ }^{\circ} \mathrm{C}$. The dehydration behavior seems to be in line with UV-Vis behavior since the relative intensity of the $22700 \mathrm{~cm}^{-1}$ feature reached its highest value after activation at $800{ }^{\circ} \mathrm{C}$. Dehydration-driven formation of active copper-oxo sites seems to be the case for $\mathrm{Cu}-\mathrm{SiO}_{2}$ as well since the methanol yield increased with increasing $\mathrm{O}_{2}$ activation temperature (Fig. 2). Formation of the active dicopper is also associated with the $\mathrm{Cu} / \mathrm{Al}$ ratio ${ }^{4,9}$, ${ }^{48}$ and the proximity of copper ions to the $\mathrm{Al}$ ions ${ }^{49}$. Here, we show that at higher $\mathrm{O}_{2}$ activation temperatures, the $22700 \mathrm{~cm}^{-1}$ feature could manifest on the $\mathrm{SiO}_{2}$ surface without requiring $\mathrm{Al}$. The feature at $22700 \mathrm{~cm}^{-1}$ observed after $\mathrm{O}_{2}$ activation at 650 and $800{ }^{\circ} \mathrm{C}$ disappeared after subsequent $\mathrm{CH}_{4}$ reaction at $200{ }^{\circ} \mathrm{C}\left(\mathrm{O}_{2}\right.$ activated at $\left.800{ }^{\circ} \mathrm{C}\right)$ as shown in Fig $5 \mathrm{~b}$ and also in the difference spectrum given in the inset of Fig $5 \mathrm{~b}$ along with other CT features at 25800, 20270 and $13380 \mathrm{~cm}^{-1}$ as indicated with blue lines. Gradual disappearance of the $22700 \mathrm{~cm}^{-1}$ feature upon $\mathrm{CH}_{4}$ reaction ${ }^{4-5,32}$ or upon $\mathrm{NO}$ reaction ${ }^{35}$ was also observed on $\mathrm{Cu}-z e o l i t e s$. Therefore, this feature along with the features observed in the difference spectrum could be ascribed to active site(s) for methane activation on $\mathrm{Cu}-\mathrm{SiO}_{2}$.

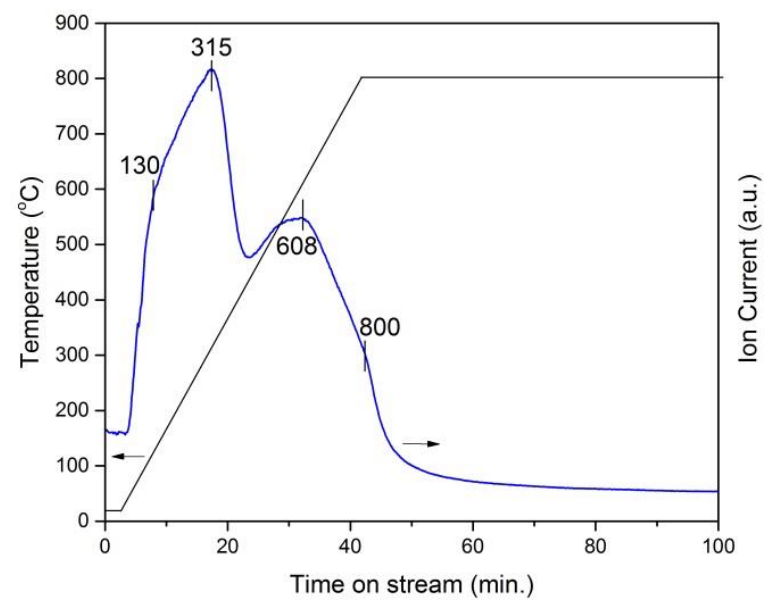

Figure 7. $\mathrm{MS}$ traces of $\mathrm{H}_{2} \mathrm{O}(\mathrm{m} / \mathrm{z}=18)$ during the $\mathrm{O}_{2}$ activation step of $\mathrm{Cu}-\mathrm{SiO}_{2}-2$. 

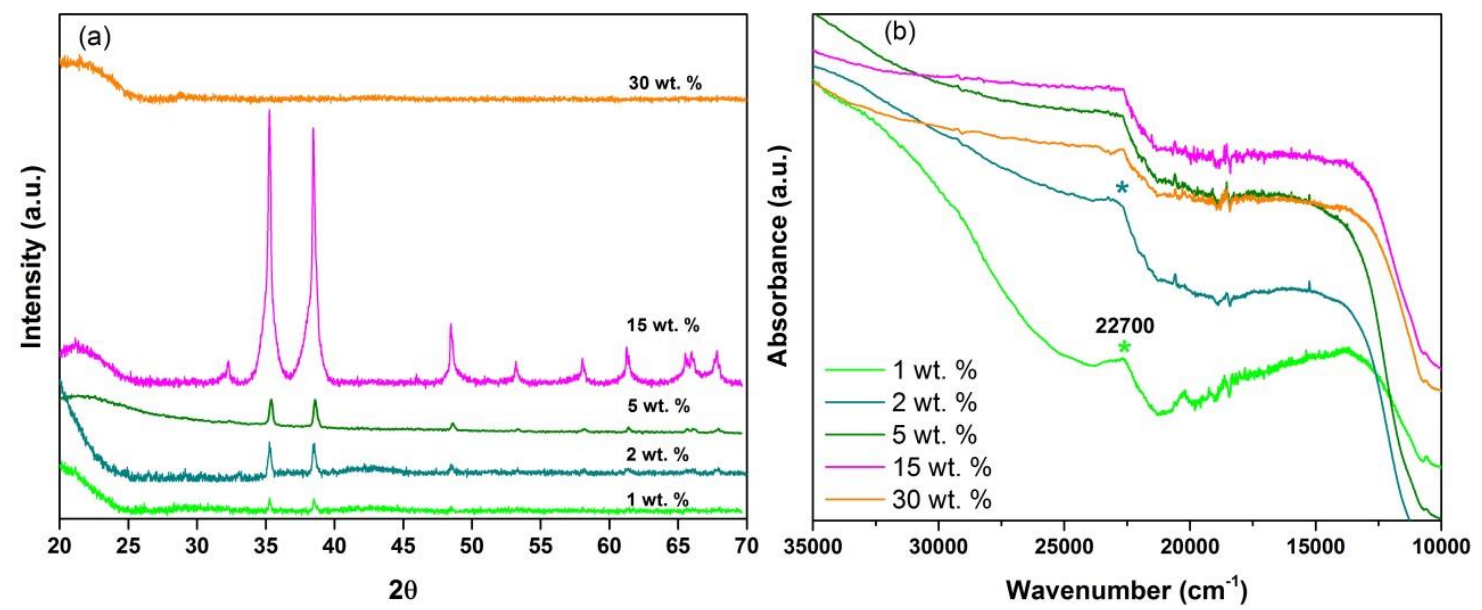

Figure 8. (a) XRD of $\mathrm{Cu}$ on silica with various loadings after calcination at $800{ }^{\circ} \mathrm{C}$ in $\mathrm{O}_{2}$. (b) $\mathrm{RT}$ $\mathrm{UV}-\mathrm{Vis}$ spectra of $\mathrm{Cu}$ on silica with various loadings after calcination at $800{ }^{\circ} \mathrm{C}$ in $\mathrm{O}_{2}$.

The $\mathrm{Cu}$ loading is an important parameter affecting the speciation of the actives sites and thus the methanol yield in $\mathrm{Cu}$-zeolites ${ }^{4}$. Therefore, we investigated the effect of metal loading on the structural and spectroscopic features of the $\mathrm{Cu}-\mathrm{SiO}_{2}$ samples after $\mathrm{O}_{2}$ activation at $800{ }^{\circ} \mathrm{C}$. Samples treated at $800{ }^{\circ} \mathrm{C}$ were investigated since they resulted in the highest methanol yields. XRD patterns shown in Fig. 8a indicate the presence of monoclinic $\mathrm{CuO}$ in all samples, with the exception of the $30 \mathrm{wt} \%$ sample, however the concentration of $\mathrm{CuO}$ nanocrystals in the samples varied with metal content. $\mathrm{Cu}-\mathrm{SiO}_{2}-1$ and $\mathrm{Cu}-\mathrm{SiO}_{2}-2$ had a low $\mathrm{CuO}$ concentration whereas the concentration of nano-crystals was much higher for $\mathrm{Cu}-\mathrm{SiO}_{2}-15$ which has a bimodal crystal size distribution. The UV-vis spectra illustrated in Fig. 8b again indicates the presence of the 22700 $\mathrm{cm}^{-1}$ feature for all of the samples. However, for samples with loadings higher than $2 \mathrm{wt} . \%$ it is difficult to ascribe this feature to a single site due to the bulky shape of the CT region between 35000 and $22000 \mathrm{~cm}^{-1}$. For the $\mathrm{Cu}-\mathrm{SiO}_{2}-1$, a broad CT band at $32200 \mathrm{~cm}^{-1}$ with a shoulder at $29000 \mathrm{~cm}^{-1}$ could also be observed. Similar CT features were ascribed to copper clusters in $\mathrm{Cu}-$ zeolites ${ }^{34}$. Since all the samples had some activity towards the conversion of methane to 
methanol, isolated dicopper sites or even $\mathrm{CuO}$ clusters with sizes below the detection limit of XRD could be active sites. We performed XRD after all of the relevant subsequent steps of the catalytic cycle for the $\mathrm{Cu}-\mathrm{SiO}_{2}-2$ (Fig. 9). All of the peaks associated with the crystal planes of $\mathrm{CuO}$ formed after the $\mathrm{O}_{2}$ activation at $800{ }^{\circ} \mathrm{C}$, shifted to higher $2 \theta$ values upon reaction with $\mathrm{CH}_{4}$ at $200{ }^{\circ} \mathrm{C}$. This could be associated with the contraction of the crystal lattice ${ }^{58}$ by the chemisorption of reaction intermediates on $\mathrm{CuO}$. Upon subsequent extraction in $\mathrm{H}_{2} \mathrm{O}$ (Step G1) which removed the chemisorbed intermediates by the formation of methanol, the XRD showed that the peaks shifted back to their original values obtained after the $\mathrm{O}_{2}$ activation step however with lower intensity. This indicates that $\mathrm{CuO}$ nano-crystals might also be involved in the activation of methane for the production of methanol on $\mathrm{Cu}-\mathrm{SiO}_{2}$

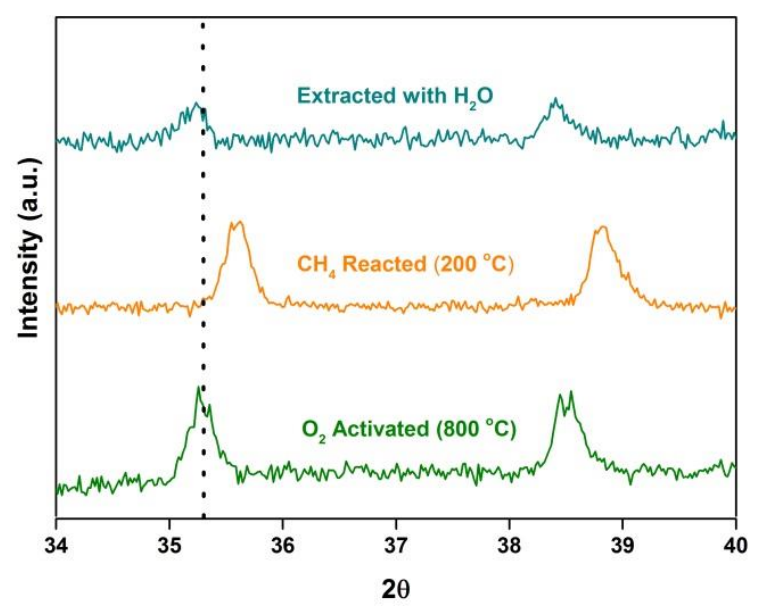

Figure 9. Section of the $\mathrm{XRD}$ pattern of $\mathrm{Cu}-\mathrm{SiO}_{2}-2$ after various steps of the catalytic cycle. Dotted line illustrates the $2 \theta$ angle of $\mathrm{CuO}$ (111) plane.

Fig. 10 compares the XANES and Fourier transformed (FT) extended x-ray absorption fine structure (EXAFS) spectra of $\mathrm{Cu}-\mathrm{SiO}_{2}-5$ (Fig. 10a \& c) and $\mathrm{Cu}-\mathrm{SiO}_{2}-30$ (Fig. 10b \& d) during progressive heating in $\mathrm{O}_{2}$ flow. XANES recorded for the $\mathrm{Cu}-\mathrm{SiO}_{2}-5$ sample showed a progressive decrease of the maximum intensity feature at around $9000 \mathrm{eV}$ which indicates a 
gradual change in local coordination of $\mathrm{Cu}$ with increasing temperature. The distinct shoulder observed at around $8986 \mathrm{eV}$ and a pre-edge feature at around $8977 \mathrm{eV}$ are the indications of the $\mathrm{Cu}^{2+}$ oxidation state. The intensity of this feature slightly increased with increasing temperature indicating that the concentration of the $\mathrm{Cu}^{2+}$ species increased in agreement with observations of $\mathrm{Cu}$ species in $\mathrm{Cu}$-zeolites ${ }^{15,23}$. The loss of the whiteline intensity can be ascribed to the dehydration of the $\mathrm{Cu}$ (II) hydroxide species ${ }^{24}$ as previously demonstrated with the TPD- $\mathrm{H}_{2} \mathrm{O}$ experiment (Fig. 7). The XANES recorded of the $\mathrm{Cu}-\mathrm{SiO}_{2}-30$ sample did not show any appreciable change in the intensities of neither the whiteline nor the shoulder around $8986 \mathrm{eV}$ with increasing temperature from 30 to $800{ }^{\circ} \mathrm{C}$ indicating that all $\mathrm{Cu}$ was in the form of $\mathrm{Cu}(\mathrm{II})$.

The FT EXAFS spectra recorded for the $\mathrm{Cu}-\mathrm{SiO}_{2}-5$ and $\mathrm{Cu}-\mathrm{SiO}_{2}-30$ (Fig. 10c\&d) during progressive heating in $\mathrm{O}_{2}$ flow show a first coordination shell centered around $1.9 \AA$ (spectra were corrected for phase shifts) and a second coordination shell centered around $2.8 \AA$. For the $\mathrm{Cu}-\mathrm{SiO}_{2}-5$, the increase in the temperature resulted in the change of the shape and the intensity of the feature around $1.9 \AA$ most probably due to the loss of coordinated oxygen atoms most likely caused by dehydration. FT-EXAFS spectra taken of the $\mathrm{Cu}-\mathrm{SiO}_{2}-30$ show no significant change with increasing temperature similar to the behavior observed during the measurement of XANES.

The EXAFS spectra recorded during the $\mathrm{O}_{2}$ activation at $800{ }^{\circ} \mathrm{C}$ at 5,60 and $120 \mathrm{~min}$ for $\mathrm{Cu}$ $\mathrm{SiO}_{2}-5$ and $\mathrm{Cu}-\mathrm{SiO}_{2}-30$ are presented in Fig. 11. No apparent changes were observed in the $\mathrm{k}^{2}$ weighted oscillatory functions for both catalysts with changes in $\mathrm{O}_{2}$ activation time. Given the fact that EXAFS is a bulk technique and considering the data in Fig. 3a which shows that the $\mathrm{O}_{2}$ activation time is an important parameter for increased methanol yield, indicate that the active sites might consist of only a small fraction of the $\mathrm{Cu}$ in $\mathrm{Cu}-\mathrm{SiO}_{2}$. 

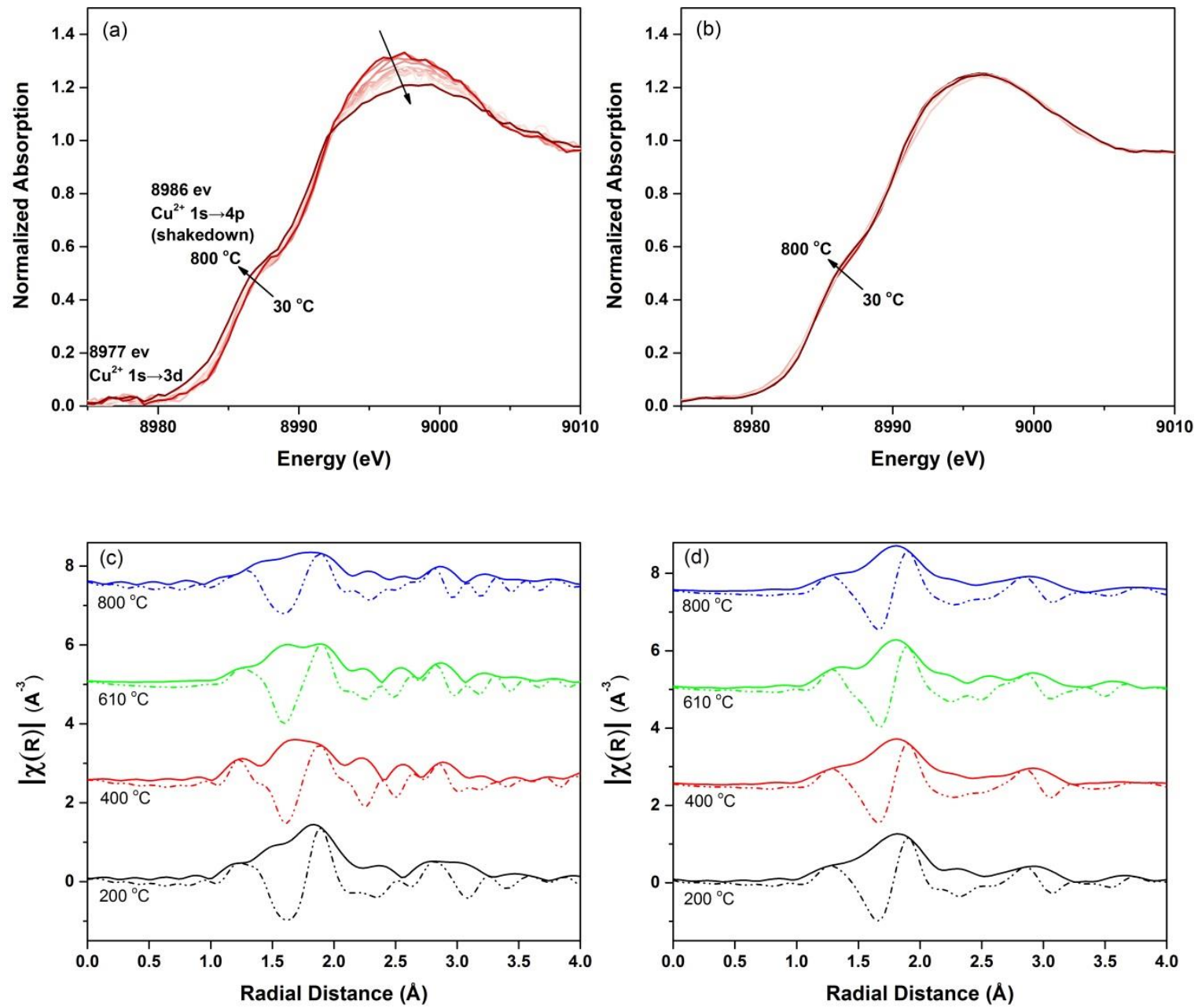

Figure 10. $\mathrm{Cu} \mathrm{K}$ edge $\mathrm{XANES}$ spectra of $\mathrm{Cu}-\mathrm{SiO}_{2}$ samples taken during the $\mathrm{O}_{2}$ activation period

(a) $\mathrm{Cu}-\mathrm{SiO}_{2}-5$, (b) $\mathrm{Cu}-\mathrm{SiO}_{2}-30$. Magnitude of the FT EXAFS spectra and the imaginary part of

(c) $\mathrm{Cu}-\mathrm{SiO}_{2}-5$ (d) $\mathrm{Cu}-\mathrm{SiO}_{2}-30$. 

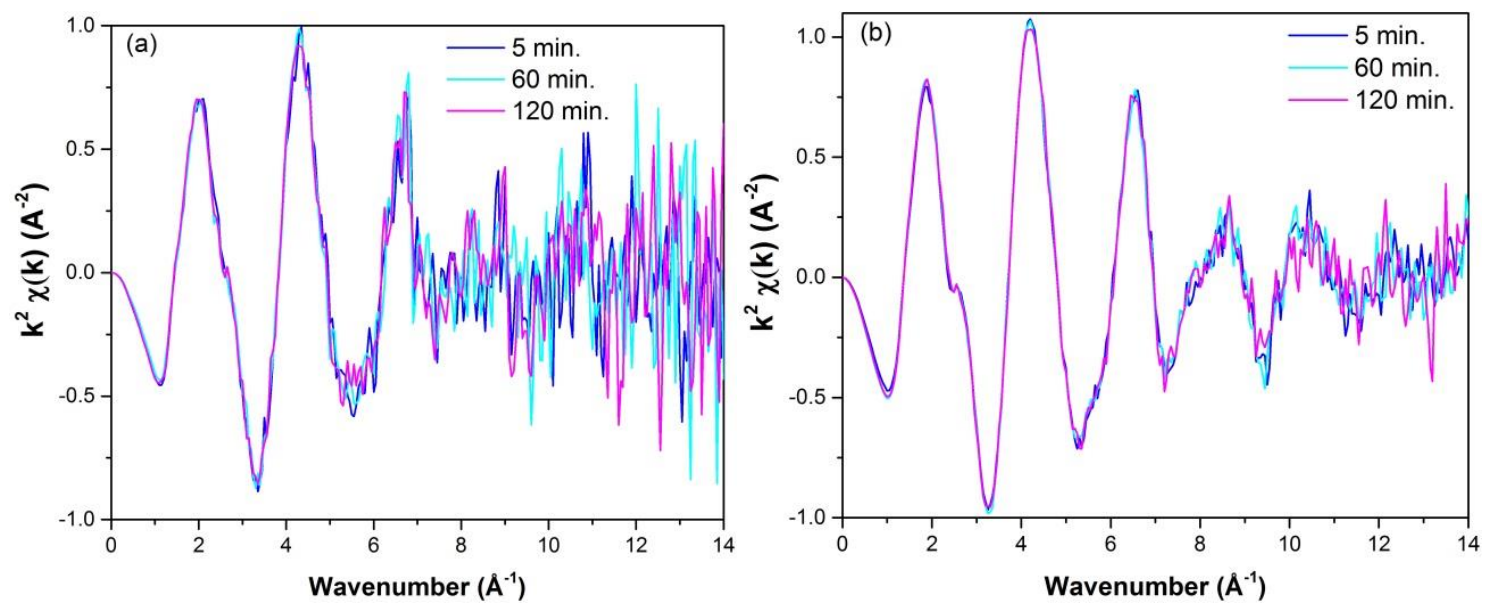

Figure 11. EXAFS spectra of (a) $\mathrm{Cu}-\mathrm{SiO}_{2}-5$, (b) $\mathrm{Cu}-\mathrm{SiO}_{2}-30$ taken during the $\mathrm{O}_{2}$ activation period at $800{ }^{\circ} \mathrm{C}$.

An important number of articles have appeared for the step-wise direct conversion of methane to methanol since the report of Groothaert et al. ${ }^{4}$ with most of them focusing on the reactivity of transition metal impregnated zeolites. However, Groothaert et al. ${ }^{4}$ had also reported the activity of $\mathrm{Cu}-\mathrm{SiO}_{2}$ with 0.6 wt. $\% \mathrm{Al}_{2} \mathrm{O}_{3}$ and 2 wt. $\% \mathrm{Cu}$ with a yield of $1 \mu \mathrm{mol}$ methanol $/ \mathrm{g}_{\text {catalyst. After }}$ activation at $450{ }^{\circ} \mathrm{C}$ in $\mathrm{O}_{2}$ a value slightly higher than our current results (Fig. 2) at the same $\mathrm{O}_{2}$ activation temperature and $\mathrm{Cu}$ wt. \% was obtained. This is most probably due to the presence Al in the $\mathrm{SiO}_{2}$ used ${ }^{4}$ which might have induced the formation of more active sites. The formation of the active $\mathrm{Cu}$-oxo species in zeolites requires the presence of framework Al sites. Addition of $\mathrm{Al}$ sites to $\mathrm{SiO}_{2}$ can create vacancies for the formation of highly dispersed $\mathrm{Cu}^{2+}$ species. Reactive copper-oxo species may form on pure silica based supports. For example, Patel et al. suggested that the reduction of $\mathrm{NO}$ by $\mathrm{CO}$ on copper-oxide supported on mesoporous silica is mostly affected by the presence of dispersed copper species based on $\mathrm{H}_{2}$-TPR data ${ }^{59}$. An et al. ${ }^{60}$ showed that after calcination at $650{ }^{\circ} \mathrm{C}, \mathrm{Cu}$ grafted SBA-15 had a mixture of copper-oxo species in the form of dispersed species and clusters, where the increased concentration of dispersed 
species correlates with the formaldehyde selectivity. Higher temperature treatment of $\mathrm{Cu}-\mathrm{SiO}_{2}$ during $\mathrm{O}_{2}$ activation might be inducing the formation of dispersed copper-oxo species which are able to activate $\mathrm{CH}_{4}$ and results in a significantly increased methanol yield. Methanol yields obtained after high temperature $\mathrm{O}_{2}$ activation on $\mathrm{Cu}-\mathrm{SiO}_{2}$ are higher or similar to those of $\mathrm{Cu}$ MOR ${ }^{5}$ and CuZSM- $5^{4,32}$ with similar $\mathrm{Cu}$ metal weight percentages. This shows that the surface concentration of the active sites is similar. On the other hand, high temperature treatment of the $\mathrm{Cu}-\mathrm{SiO}_{2}$ might also have caused changes in the microstructure of the silica support (as indicated by XRD in Fig. 5) as it is very well known that transformations from amorphous silica or from tridymite to cristobalite phase may occur at high temperature in the presence of a catalyst ${ }^{61-64}$. The presence of cristobalite phases in the $\mathrm{Mn}-\mathrm{Na}-\mathrm{W} / \mathrm{SiO}_{2}$ catalysts was advantageous both for methane conversion and the selectivity for the $\mathrm{C}_{2}$ species in the oxidative coupling of methane as compared to amorphous silica support ${ }^{63-64}$. A similar process may also occur in $\mathrm{Cu}-\mathrm{SiO}_{2}$ catalyst where the crystalline domains could potentially accommodate $\mathrm{Cu}$-oxo species. Using different synthesis routes ${ }^{15,25,29}$ or conducting the $\mathrm{CH}_{4}$ reaction at high pressure ${ }^{45}$ resulted in much higher methanol yields in $\mathrm{Cu}$-zeolites. This might also be expected for $\mathrm{Cu}-\mathrm{SiO}_{2}$ if different preparation routes and different reactions conditions such as high pressure $\mathrm{CH}_{4}$ treatment are applied.

\section{Conclusion}

$\mathrm{Cu}-\mathrm{SiO}_{2}$ is an effective catalyst for the direct conversion of methane to methanol in a stepwise manner. The $\mathrm{O}_{2}$ activation temperature and methane partial pressure affected the methanol yield significantly. When the activation was carried out at $800{ }^{\circ} \mathrm{C}$, yields similar to that of $\mathrm{Cu}-$ MOR ${ }^{5}$ and $\mathrm{Cu}-\mathrm{ZSM} 5{ }^{4}$ activated at around $400{ }^{\circ} \mathrm{C}$ were obtained. The methanol yield was also affected by the metal content. The yield per mole of copper exponentially increased as the weight 
percentage of copper decreased from $30 \%$ to $1 \%$. Increasing $\mathrm{p}_{\mathrm{CH} 4}$ from 0.05 to 1 atm resulted in a 5-fold increase in yield after activation at $450{ }^{\circ} \mathrm{C}$, however it resulted in at least $20 \%$ lower yields after activation at $800{ }^{\circ} \mathrm{C}$ showing that different active sites were formed at different conditions with the possibility of having different reaction orders towards $\mathrm{CH}_{4}$ activation. UVVis suggested that the copper-oxo site associated with the $22700 \mathrm{~cm}^{-1} \mathrm{CT}$ band could be one of the active sites. For the $\mathrm{Cu}-\mathrm{SiO}_{2}-2, \mathrm{XRD}$ indicated the formation of $\mathrm{CuO}$ nanoparticles after activation at $450{ }^{\circ} \mathrm{C}$ which were absent at $650{ }^{\circ} \mathrm{C}$ and appeared again with a much lower concentration at $800{ }^{\circ} \mathrm{C}$. MS signals during the $\mathrm{O}_{2}$ activation together with the XANES data showed that the formation of the active sites requires the dehydration of the sample. The data presented here showed that formation of active copper species that were previously thought to be formed only on crystalline zeolite supports can be formed on a support material such $\mathrm{as}_{\mathrm{SiO}_{2}}$ if proper conditions are met. Therefore, many other supports might be of use for supporting active $\mathrm{Cu}$ species for methane to methanol conversion.

\section{AUTHOR INFORMATION}

Corresponding Author

*Corresponding author; e-mail: Carl.Mesters@shell.com; jeroen.vanbokhoven@chem.ethz.ch; Tel.: + 41446325542

Present Addresses

$\dagger$ : Koç University, Chemical and Biological Engineering Department, Sarıyer, 34450, Istanbul, Turkey. 
Author Contributions

The manuscript was written through contributions of all authors. All authors have given approval to the final version of the manuscript.

\section{ACKNOWLEDGMENT}

SEB acknowledges the financial support of Turkish Scientific and Technological Research Council (TÜBİTAK) for the international postdoctoral scholarship (2219). Electron microscopy work was performed at ScopeM (ETH Zurich).

\section{REFERENCES}

1. Ahlquist, M.; Nielsen, R. J.; Periana, R. A.; Goddard III, W. A., Product Protection, the Key to Developing High Performance Methane Selective Oxidation Catalysts, Journal of American Chemical Society 2009, 131, 17110-17115.

2. Ravi, M.; Ranocchiari, M.; van Bokhoven, J. A., A Critical Assessment of the Direct Catalytic Oxidation of Methane to Methanol, Angewandte Chemie International Edition 2017.

3. Lange, J. P.; de Jong, K. P.; Ansorge, J.; Tijm, P. J. A., Keys to Methane Conversion Technologies, Studies in Surface Science and Catalysis 1997, 107, 81-86.

4. Groothaert, M. H.; Smeets, P. J.; Sels, B. F.; Jacobs, P. A.; Schoonheydt, R. A., Selective Oxidation of Methane by the Bis( $\mu$-Oxo)Dicopper Core Stabilized on ZSM-5 and Mordenite Zeolites, Journal of the American Chemical Society 2005, 127 (5), 1394-1395.

5. Alayon, E. M.; Nachtegaal, M.; Ranocchiari, M.; van Bokhoven, J. A., Catalytic Conversion of Methane to Methanol over Cu-Mordenite, Chemical Communications 2012, 48 (3), 404-406.

6. Wulfers, M. J.; Teketel, S.; Ipek, B.; Lobo, R. F., Conversion of Methane to Methanol on Copper Containing Small-Pore Zeolites and Zeotypes, Chemical Communications 2015, 51, 4447. 7. Ipek, B.; Wulfers, M. J.; Kim, H.; Göltl, F.; Hermans, I.; Smith, J. P.; Booksh, K. S.; Brown, C. M.; Lobo, R. F., Formation of $\left[\mathrm{Cu}_{2} \mathrm{O}_{2}\right]^{2+}$ and $\left[\mathrm{Cu}_{2} \mathrm{O}\right]^{2+}$ toward $\mathrm{C}-\mathrm{H}$ Bond Activation in Cu-SSZ-13 and Cu-SSZ-39, ACS Catalysis 2017, 7 (7), 4291-4303.

8. $\quad$ Pappas, D. K.; Borfecchia, E.; Dyballa, M.; Pankin, I. A.; Lomachenko, K. A.; Martini, A.; Signorile, M.; Teketel, S.; Arstad, B.; Berlier, G.; Lamberti, C.; Bordiga, S.; Olsbye, U.; Lillerud, K. P.; Svelle, S.; Beato, P., Methane to Methanol: Structure-Activity Relationships for Cu-CHA, Journal of the American Chemical Society 2017, 139 (42), 14961-14975.

9. Park, M. B.; Ahn, S. H.; Ranocchiari, M.; van Bokhoven, J. A., Comparative Study of Diverse Cu-Zeolites for Conversion of Methane-to-Methanol, ChemCatChem 2017. 
10. Labinger, J. A., Selective Alkane Oxidation: Hot and Cold Approaches to a Hot Problem, Journal of Molecular Catalysis A: Chemical 2004, 220 (1), 27-35.

11. Chen, P. P. Y.; Yang, R. B. G.; Lee, J. C. M.; Chan, S. I., Facile O-Atom Insertion into C$\mathrm{C}$ and C-H Bonds by a Trinuclear Copper Complex Designed to Harness a Singlet Oxene, Proc. Natl. Acad. Sci. U. S. A. 2007, 104 (37), 14570-14575.

12. Que, L.; Tolman, W. B., Biologically Inspired Oxidation Catalysis, Nature 2008, 455 (7211), 333-340.

13. Balasubramanian, R.; Smith, S. M.; Rawat, S.; Yatsunyk, L. A.; Stemmler, T. L.; Rosenzweig, A. C., Oxidation of Methane by a Biological Dicopper Centre, Nature 2010, 465 (7294), 115-U131.

14. Haack, P.; Limberg, C., Molecular CuII-O-CuII Complexes: Still Waters Run Deep, Angewandte Chemie-International Edition 2014, 53 (17), 4282-4293.

15. Bozbag, S. E.; Alayon, E. M. C.; Pechacek, J.; Nachtegaal, M.; Ranocchiari, M.; van Bokhoven, J. A., Methane to Methanol over Copper Mordenite: Yield Improvement through Multiple Cycles and Different Synthesis Techniques, Catalysis Science \& Technology 2016, 6 (13), 5011-5022.

16. Beznis, N. V.; Weckhuysen, B. M.; Bitter, J. H., Cu-ZSM-5 Zeolites for the Formation of Methanol from Methane and Oxygen: Probing the Active Sites and Spectator Species, Catal. Lett. 2010, 138 (1-2), 14-22.

17. Kim, Y.; Kim, T. Y.; Lee, H.; Yi, J., Distinct Activation of Cu-MOR for Direct Oxidation of Methane to Methanol, Chemical Communications 2017, 53 (29), 4116-4119.

18. Sheppard, T.; Hamill, C. D.; Goguet, A.; Rooney, D. W.; Thompson, J. M., A Low Temperature, Isothermal Gas-Phase System for Conversion of Methane to Methanol over $\mathrm{Cu}-$ ZSM-5, Chemical Communications 2014, 50, 11053-11055.

19. Sushkevich, V. L.; Palagin, D.; Ranocchiari, M.; van Bokhoven, J. A., Selective Anaerobic Oxidation of Methane Enables Direct Synthesis of Methanol, Science 2017, 356 (6337), 523-527. 20. Hutchings, G. J., Methane Activation by Selective Oxidation, Top. Catal. 2016, 59 (8-9), 658-662.

21. Tsai, M. L.; Hadt, R. G.; Vanelderen, P.; Sels, B. F.; Schoonheydt, R. A.; Solomon, E. I., $\mathrm{Cu}_{2} \mathrm{O}(2+)$ Active Site Formation in Cu-ZSM-5: Geometric and Electronic Structure Requirements for $\mathrm{N}_{2} \mathrm{O}$ Activation, Journal of the American Chemical Society 2014, 136 (9), 3522-3529.

22. Narsimhan, K.; Iyoki, K.; Dinh, K.; Roman-Leshkov, Y., Catalytic Oxidation of Methane into Methanol over Copper-Exchanged Zeolites with Oxygen at Low Temperature, ACS Central Science 2016, 2 (6), 424-429.

23. Alayon, E. M. C.; Nachtegaal, M.; Bodi, A.; Ranocchiari, M.; van Bokhoven, J. A., Bis( $\mu$ Oxo) Versus Mono( $\mu$-Oxo)Dicopper Cores in a Zeolite for Converting Methane to Methanol: An in Situ Xas and Dft Investigation, Physical Chemistry Chemical Physics 2015, 17 (12), 7681-7693. 24. Borfecchia, E.; Lomachenko, K. A.; Giordanino, F.; Falsig, H.; Beato, P.; Soldatov, A. V.; Bordiga, S.; Lamberti, C., Revisiting the Nature of $\mathrm{Cu}$ Sites in the Activated Cu-SSZ-13 Catalyst for Scr Reaction, Chemical Science 2015, 6 (1), 548-563.

25. Grundner, S.; Markovits, M. A. C.; Li, G.; Tromp, M.; Pidko, E. A.; Hensen, E. J. M.; Jentys, A.; Sanchez-Sanchez, M.; Lercher, J. A., Single-Site Trinuclear Copper Oxygen Clusters in Mordenite for Selective Conversion of Methane to Methanol, Nature Communications 2015, 6. 26. Alayon, E. M. C.; Nachtegaal, M.; Kleymenov, E.; van Bokhoven, J. A., Determination of the Electronic and Geometric Structure of Cu Sites During Methane Conversion over Cu-Mor with 
X-Ray Absorption Spectroscopy, Microporous and Mesoporous Materials 2013, 166 (0), 131 136.

27. LoJacono, M.; Fierro, G.; Dragone, R.; Feng, X. B.; dItri, J.; Hall, W. K., Zeolite Chemistry of Cuzsm-5 Revisited, J. Phys. Chem. B 1997, 101 (11), 1979-1984.

28. Kuroda, Y.; Konno, S.; Yoshikawa, Y.; Maeda, H.; Kubozono, Y.; Hamano, H.; Kumashiro, R.; Nagao, M., Stabilization of Copper Metal Clusters in Mordenite Micropores Water Treatment of Evacuated Copper Ion-Exchanged Mordenite at 300 K, J. Chem. Soc.-Faraday Trans. 1997, 93 (11), 2125-2130.

29. Grundner, S.; Luo, W.; Sanchez-Sanchez, M.; Lercher, J. A., Synthesis of Single-Site Copper Catalysts for Methane Partial Oxidation, Chemical Communications 2016, 52 (12), 25532556.

30. Sheppard, T.; Daly, H.; Goguet, A.; Thompson, J. M., Improved Efficiency for Partial Oxidation of Methane by Controlled Copper Deposition on Surface-Modified ZSM-5, Chemcatchem 2016, 8 (3), 562-570.

31. Llabrés i Xamena, F. X.; Fisicaro, P.; Berlier, G.; Zecchina, A.; Palomino, G. T.; Prestipino, C.; Bordiga, S.; Giamello, E.; Lamberti, C., Thermal Reduction of $\mathrm{Cu}^{2+}$-Mordenite and Re-Oxidation Upon Interaction with $\mathrm{H}_{2} \mathrm{O}, \mathrm{O}_{2}$, and $\mathrm{NO}$, The Journal of Physical Chemistry $B$ 2003, 107 (29), 7036-7044.

32. Smeets, P. J.; Groothaert, M. H.; Schoonheydt, R. A., Cu Based Zeolites: A Uv-Vis Study of the Active Site in the Selective Methane Oxidation at Low Temperatures, Catal. Today 2005, 110 (3-4), 303-309.

33. Palomino, G. T.; Fisicaro, P.; Bordiga, S.; Zecchina, A.; Giamello, E.; Lamberti, C., Oxidation States of Copper Ions in Zsm-5 Zeolites. A Multitechnique Investigation, The Journal of Physical Chemistry B 2000, 104 (17), 4064-4073.

34. Giordanino, F.; Vennestrom, P. N. R.; Lundegaard, L. F.; Stappen, F. N.; Mossin, S.; Beato, P.; Bordiga, S.; Lamberti, C., Characterization of Cu-Exchanged SSZ-13: A Comparative Ftir, UvVis, and Epr Study with Cu-ZSM-5 and Cu-Beta with Similar Si/Al and Cu/Al Ratios, Dalton Transactions 2013, 42 (35), 12741-12761.

35. Groothaert, M. H.; van Bokhoven, J. A.; Battiston, A. A.; Weckhuysen, B. M.; Schoonheydt, R. A., Bis( $\mu$-Oxo)Dicopper in Cu-ZSM-5 and Its Role in the Decomposition of No: A Combined in Situ Xafs, UV-Vis-near-IR, and Kinetic Study, Journal of the American Chemical Society 2003, 125 (25), 7629-7640.

36. Bordiga, S.; Groppo, E.; Agostini, G.; van Bokhoven, J. A.; Lamberti, C., Reactivity of Surface Species in Heterogeneous Catalysts Probed by In Situ X-ray Absorption Techniques, Chemical Reviews 2013, 113 (3), 1736-1850.

37. van Bokhoven, J. A.; Lamberti, C., X-Ray Absorption and X-ray Emission Spectroscopy: Theory and Applications. John Wiley \& Sons: Chichester (UK), 2016.

38. Zhao, Z. J.; Kulkarni, A.; Vilella, L.; Norskov, J. K.; Studt, F., Theoretical Insights into the Selective Oxidation of Methane to Methanol in Copper-Exchanged Mordenite, Acs Catalysis 2016, 6 (6), 3760-3766.

39. Kulkarni, A. R.; Zhao, Z. J.; Siahrostami, S.; Norskov, J. K.; Studt, F., Monocopper Active Site for Partial Methane Oxidation in Cu-Exchanged 8mr Zeolites, Acs Catalysis 2016, 6 (10), 6531-6536.

40. Palagin, D.; Knorpp, A. J.; Pinar, A. B.; Ranocchiari, M.; van Bokhoven, J. A., Assessing the Relative Stability of Copper Oxide Clusters as Active Sites of a Cumor Zeolite for Methane to Methanol Conversion: Size Matters?, Nanoscale 2017, 9 (3), 1144-1153. 
41. Yumura, T.; Hirose, Y.; Wakasugi, T.; Kuroda, Y.; Kobayashi, H., Roles of Water Molecules in Modulating the Reactivity of Dioxygen-Bound Cu-Zsm-5 toward Methane: A Theoretical Prediction, Acs Catalysis 2016, 6 (4), 2487-2495.

42. Mahyuddin, M. H.; Staykov, A.; Shiota, Y.; Yoshizawa, K., Direct Conversion of Methane to Methanol by Metal-Exchanged Zsm-5 Zeolite (Metal = Fe, Co, Ni, Cu), Acs Catalysis 2016, 6 (12), 8321-8331.

43. Woertink, J. S.; Smeets, P. J.; Groothaert, M. H.; Vance, M. A.; Sels, B. F.; Schoonheydt, R. A.; Solomon, E. I., A Cu $2 \mathrm{O}(2+)$ Core in Cu-ZSM-5, the Active Site in the Oxidation of Methane to Methanol, Proc. Natl. Acad. Sci. U. S. A. 2009, 106 (45), 18908-18913.

44. Alayon, E. M. C.; Nachtegaal, M.; Bodi, A.; van Bokhoven, J. A., Reaction Conditions of Methane-to-Methanol Conversion Affect the Structure of Active Copper Sites, ACS Catalysis 2014, 4 (1), 16-22.

45. Tomkins, P.; Mansouri, A.; Bozbag, S. E.; Krumeich, F.; Park, M. B.; Alayon, E. M. C.; Ranocchiari, M.; van Bokhoven, J. A., Isothermal Cyclic Conversion of Methane into Methanol over Copper-Exchanged Zeolite at Low Temperature, Angewandte Chemie-International Edition 2016, 55 (18), 5467-5471.

46. Tomkins, P.; Ranocchiari, M.; van Bokhoven, J. A., Direct Conversion of Methane to Methanol under Mild Conditions over Cu-Zeolites and Beyond, Accounts of Chemical Research 2017, 50 (2), 418-425.

47. Li, Y.; An, D.; Zhang, Q.; Wang, Y., Copper-Catalyzed Selective Oxidation of Methane by Oxygen: Studies on Catalytic Behavior and Functioning Mechanism of Cuox/Sba-15, J. Phys. Chem. C 2008, 112, 13700-13708.

48. Vanelderen, P.; Hadt, R. G.; Smeets, P. J.; Solomon, E. I.; Schoonheydt, R. A.; Sels, B. F., Cu-Zsm-5: A Biomimetic Inorganic Model for Methane Oxidation, J. Catal. 2011, 284 (2), 157164.

49. Markovits, M. A. C.; Jentys, A.; Tromp, M.; Sanchez-Sanchez, M.; Lercher, J. A., Effect of Location and Distribution of Al Sites in Zsm-5 on the Formation of Cu-oxo Clusters Active for Direct Conversion of Methane to Methanol, Top. Catal. 2016, 59 (17-18), 1554-1563.

50. Huang, Z.; Cui, F.; Kang, H.; Chen, J.; Zhang, X.; Xia, C., Highly Dispersed SilicaSupported Copper Nanoparticles Prepared by Precipitation-Gel Method: A Simple but Efficient and Stable Catalyst for Glycerol Hydrogenolysis, Chem. Mater. 2008, 20, 5090-5099.

51. Zhang, R.; Sun, Y.-h.; Peng, S.-y., Dehydrogenation of Methanol to Methyl Formate over

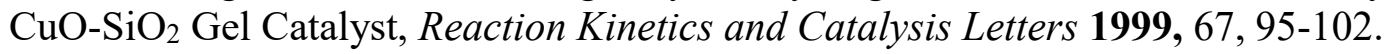

52. de Sousa, E. M. B.; de Magalhaes, W. F.; Mohallem, N. D. S., Characterization of Silica Nanocomposites Obtained by Sol-Gel Process Using Positron Annihilation Spectroscopy, Journal of Physics and Chemistry of Solids 1999, 60 211-221.

53. Sivasubramanian, G.; Shanmugam, C.; Parameswaran, V. R., Copper(II) Immobilized on Silica Extracted from Foxtail Millet Husk: A Heterogeneous Catalyst for the Oxidation of Tertiary Amines under Ambient Conditions, Journal of Porous Materials 2013, 20, 417-430.

54. Vanelderen, P.; Vancauwenbergh, J.; Tsai, M.-L.; Hadt, R. G.; Solomon, E. I.; Schoonheydt, R. A.; Sels, B. F., Spectroscopy and Redox Chemistry of Copper in Mordenite, Chemphyschem 2014, 15 (1), 91-99.

55. Le, H. V.; Parishan, S.; Saaltchik, A.; Gobel, C.; Schlesiger, C.; Malzer, W.; Trunschke, A.; Schomacker, R.; Thomas, A., Solid-State Ion-Exchanged Cu/Mordenite Catalysts for the Direct Conversion of Methane to Methanol, Acs Catalysis 2017, 7 (2), 1403-1412. 
56. Narsimhan, K.; Michaelis, V. K.; Mathies, G.; Gunther, W. R.; Griffin, R. G.; RomanLeshkov, Y., Methane to Acetic Acid over Cu-Exchanged Zeolites: Mechanistic Insights from a Site-Specific Carbonylation Reaction, Journal of the American Chemical Society 2015, 137 (5), 1825-1832.

57. Verma, A. A.; Bates, S. A.; Anggara, T.; Paolucci, C.; Parekh, A. A.; Kamasamudram, K.; Yezerets, A.; Miller, J. T.; Delgass, W. N.; Schneider, W. F.; Ribeiro, F. H., No Oxidation: A Probe Reaction on Cu-Ssz-13, J. Catal. 2014, 312, 179-190.

58. Bozbag, S. E.; Unal, U.; Kurykin, M. A.; Ayala, C. J.; Aindow, M.; Erkey, C., Thermodynamic Control of Metal Loading and Composition of Carbon Aerogel Supported $\mathrm{Pt}-\mathrm{Cu}$ Alloy Nanoparticles by Supercritical Deposition, Journal Physical Chemistry C 2013, 117, 6777. 59. Patel, A.; Shukla, P.; Rufford, T.; Wang, S.; Chen, J.; Rudolph, V.; Zhu, Z., Catalytic Reduction of NO by CO over Copper-Oxide Supported Mesoporous Silica, Applied Catalysis A: General 2011, 55- 65, 409-410.

60. An, D.; Zhang, Q.; Wang, Y., Copper Grafted on SBA-15 as Efficient Catalyst for the Selective Oxidation of Methane by Oxygen, Catal. Today 2010, 157 143-148

61. Roy, D. M.; Roy, R. Tridymite-cristobalite relations and stable solid solutions. The American Mineralogist 1964, 49, 952-962.

62. Arahori, T.; Suzuki, T. Transformation of tridymite to cristobalite below $1470^{\circ} \mathrm{C}$ in silica refractories. Journal of Materials Science 1987, 22, 2248-2252.

63. Ji, S.; Xiao, T.; Li, S.; Chou, L.; Zhang, B.; Xu, C.; Hou, R.; York, A. P. E.; Green, M. L. H. Surface WO4 tetrahedron: the essence of the oxidative coupling of methane over M-W$\mathrm{Mn} / \mathrm{SiO} 2$ catalysts. J. Catal. 2003, 220 47-56.

64. Palermo, A.; Vazquez, J. P. H.; Lee, A. F.; Tikhov, M. S.; Lambert, R. M. Critical Influence of the Amorphous Silica-to-Cristobalite Phase Transition on the Performance of $\mathrm{Mn} / \mathrm{Na} 2 \mathrm{WO} 4 / \mathrm{SiO} 2$ Catalysts for the Oxidative Coupling of Methane. J. Catal. 1998, 177, 259266. 
Table of contents image
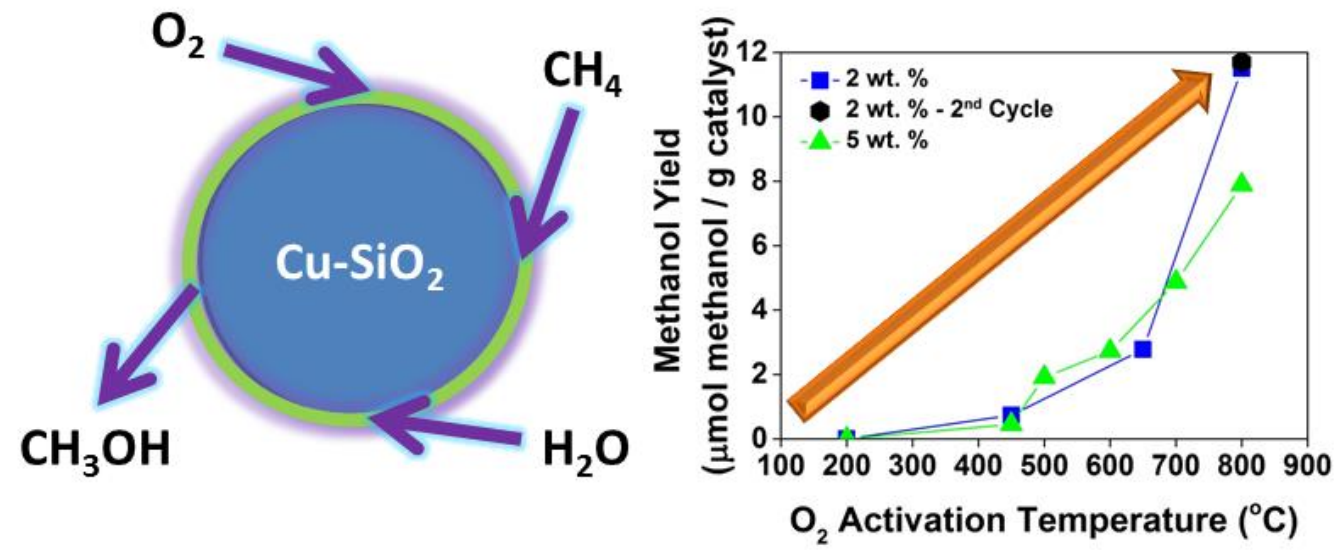